\title{
Dose and outcome: The hurdle of neutropenia (Review)
}

\author{
MAURIZIO MARANGOLO ${ }^{1}$, CARMELO BENGALA $^{2}$, PIER FRANCO CONTE $^{2}$, MARCO DANOVA $^{3}$, \\ PAOLO PRONZATO ${ }^{4}$, GIOVANNI ROSTI ${ }^{1}$ and PAOLA SAGRADA ${ }^{3}$

\begin{abstract}
${ }^{1}$ Azienda USL S. Maria delle Croci, Dipartimento di Oncologia ed Ematologia, Unità Operativa di Oncologia Medica, Ravenna; ${ }^{2}$ Divisione di Oncologia Medica, Dipartimento di Oncologia ed Ematologia, Ospedale Università, Modena; ${ }^{3}$ Policlinico S. Matteo IRCCS, Medicina Interna e Oncologia Medica, Pavia;

${ }^{4}$ Azienda USL 5 Spezzino, Oncologia Medica ed Ematologia, La Spezia, Italy
\end{abstract}

Received December 21, 2005; Accepted February 16, 2006

\begin{abstract}
The development of chemotherapy in the early 1970s resulted in the availability of curative therapeutic strategies for hematological malignancies and several types of solid tumors. It is evident that drugs should be used at their optimal dose and schedule, and drug combinations should be given at consistent intervals. According to the mathematical models that suggested the direct dose-response relationship in the improvement of outcomes in cancer chemotherapy, the dose intensity and, more recently, the dose-dense approach was considered one of the most important tools in conventional chemotherapy. Anticancer drugs are often associated with myelotoxicity, and reducing the dose or increasing the time interval between each cycle of treatment is a frequent empiric approach. Unfortunately, a dose reduction of $\geq 20 \%$ causes a loss of $50 \%$ in the cure rate, particularly in chemosensitive tumors. To accelerate bone marrow recovery and prevent the onset of severe myelosuppression and its complications, the standard use of granulocyte colony-stimulating factors (G-CSF), such as filgrastim and the long-acting pegfilgrastim, is recommended. The aim of this review is to analyze how dose intensification concepts and dose-dense regimens are able to increase the cure rate of chemosensitive solid tumors and lymphomas.
\end{abstract}

\section{Contents}

1. Introduction

2. Study design and methods

3. Has a reduction of dose intensity been detrimental to outcome and are myelotoxic regimens involved in the strategy to achieve a cure?

Correspondence to: Dr Maurizio Marangolo, Azienda USL S. Maria delle Croci, Oncologia Medica, 5 v.le Randi, Ravenna, Italy E-mail:m.marangolo@libero.it

Key words: high dose chemotherapy, dose-dense chemotherapy, growth factors (G-CSF), filgrastim, pegfilgrastim
4. The results on employment of G-CSF or pegfilgrastim to reduce myelotoxicity and maintaining dose intensity

5. 'Dose-dense' chemotherapy

6. Conclusions

\section{Introduction}

Of the many challenges of medicine, the treatment and curing of cancer in the last 20 years has experienced great progress. The development of chemotherapy in the early 1970 s resulted in the availability of curative therapeutic strategies for patients with hematological malignancies and several types of solid tumors. These advances confirmed the principle that chemotherapy could indeed cure cancer and provided the rationale for integrating chemotherapy into combined modality programs with surgery and radiation therapy, chiefly but not exclusively, in the early stages of disease. As research in the medical treatment of cancer progressed, it became evident that drugs should be used at their optimal dose and schedule, and drug combinations should be given at consistent intervals. Moreover, a large number of clinical trials have been designed according to mathematical models that suggested the direct dose-response relationship in the improvement of outcomes in cancer chemotherapy, and dose intensity was considered to be one of the most important tools in conventional chemotherapy (1-4).

The dose-dense approach to increase dose intensity is based on preclinical models of the growth of cancer cells characterized by non-exponential Gompertzian kinetics. In this model, according to the Norton-Simon hypothesis, small tumors grow faster than large tumors. Moreover, the regrowth of cancer cells is a function of cytoreduction, such that the greater the tumor cell kill, the faster the regrowth. This means that cytoreductive chemotherapy will lead to a faster regrowth of cancer cells in the intervals between cycles. Therefore, chemotherapy must be delivered in the shortest possible intervals to be most effective (5).

Because anticancer drugs are associated with side effects, mainly myelotoxicity, it is often appealing for clinicians to avoid acute toxicity by simply reducing the dose or increasing the time interval between each cycle of treatment. 
Such empiric modifications in dose represent a major reason for treatment failure in patients with drug-sensitive tumors who are receiving chemotherapy in either the adjuvant or advanced disease setting; on average, as confirmed in preclinical models, a dose reduction $\geq 20 \%$ gives rise to a loss of $50 \%$ in the cure rate (6). To accelerate bone marrow recovery and prevent the onset of severe myelosuppression and its complications, the standard use of granulocyte colonystimulating factors (G-CSF), such as filgrastim and the longacting pegfilgrastim, has reduced the incidence and severity of myelotoxicity and made feasible the right therapeutic dose. Pegfilgrastim is a long acting form of filgrastim, created by covalently binding a 20,000 dalton PEG molecule to the $\mathrm{N}$-terminal methionine residue of filgrastim. Pegfilgrastim has a minimal renal clearance, leaving neutrophil-mediated clearance as the predominant method of elimination. This 'self regulating' clearance mechanism makes it possible for the serum levels of pegfilgrastim to remain elevated during $\mathrm{CIN}$ and then decline as the ANC recovers.

\section{Study design and methods}

By using electronic devices and support (PubMed, Medline), we reviewed literature regarding breast cancer, malignant lymphomas, ovarian cancer, soft tissue sarcomas, small cell lung cancer, and germ cell tumors focusing particularly on whether i) if reduction of the dose intensity is detrimental to outcome; ii) if myelotoxicity is an acceptable adverse event when a cure is the main objective of the treatment; iii) if there are results on 'dose-dense' chemotherapy; and iv) if the use of G-CSF (filgrastim or pegfilgrastim) contributes to the cure of chemosensitive tumors by reducing neutropenia, maintaining dose intensity, and allowing dose-dense.

For this review, we considered the standard chemotherapeutic regimens including G-CSF. Papers published before 1990 were not reviewed unless they were considered historical references.

\section{Has a reduction of dose intensity been detrimental to outcome and are myelotoxic regimens involved in the strategy to achieve a cure?}

Breast cancer. Among solid tumors, breast cancer represents a challenging topic for two main reasons: the high incidence in Western countries, and the good results achieved by precocious diagnosis and integrated therapies. It is considered a chemosensitive tumor, and laboratory and clinical data show that there is a steep dose-response curve. Thus, dose reduction is associated with the fold-decrease of tumor cellkill.

The impact of maintaining chemotherapy dose intensity on disease-free survival has been shown in clinical trials of both advanced disease and in an adjuvant setting. In advanced disease, Hryniuk et al showed a significant relationship between the dose intensities of combination chemotherapy and response rate in a retrospective analysis (2). This was suggested for CMF as well as for doxorubicin-based regimens. Petit et al retrospectively compared the antitumor activity of 5-fluorouracil and cyclophosphamide in combination with either 50 or $100 \mathrm{mg} / \mathrm{m}^{2}$ epirubicin, as a neoadjuvant treatment in stage II-III breast cancer (7). Despite the small number of patients, there was a significantly high response rate in the group receiving the highest dose of epirubicin $(82.5 \%$ vs. $61.5 \%)$. It is worth noting that patients who overexpressed HER-2 and were treated with a high dose of epirubicin had a significantly higher response rate $(100.0 \%$ vs. $12.5 \%$ ). Foncan et al prospectively compared the antitumor efficacy of different dose levels of epirubicin (50 vs. $100 \mathrm{mg} / \mathrm{m}^{2}$ ) in combination with fixed doses of cyclophosphamide and 5-fluorouracil in untreated advanced breast cancer (8). A significant improvement in response rate, response duration and time-to-progression was shown in the group receiving the high dose of epirubicin. Overall survival was similar in the two groups.

In an adjuvant setting, the first clinical evidence was reported by Bonadonna et al (9). In a retrospective 30-year follow-up study, they showed that in 1,020 patients treated with $\mathrm{CMF}$ in randomized and observational studies, the disease-free and overall survival were significantly superior in the treated group, and in those who had been given at least $85 \%$ of the planned dose in this subset of patients (10). Another important study by the French Group demonstrated that high doses of epirubicin given in an adjuvant setting to high-risk breast cancer patients improved the 10-year survival with a satisfactory cardiovascular tolerability (11). These data are in agreement with a retrospective study by the CALGB group reporting on adjuvant chemotherapy in 6,487 patients entered in several trials, including CALGB 8541, and randomized to different doses of adjuvant chemotherapy; the patients treated with high doses had a $12 \%$ better chance of remaining alive and disease-free at a median follow-up of 9.6 years than those treated with low dose chemotherapy (12). Maintaining full-dose chemotherapy is often hampered by the occurrence of myelosuppression, with chemotherapyinduced neutropenia being the primary cause of course delays and dose reductions in patients with early-stage breast cancer.

A survey of more than 1,100 patients with operable breast cancer treated at 13 oncology institutions (academic, community practices and managed care) found that $30 \%$ of patients received $<85 \%$ of the standard reference dose. The dose was delayed or reduced in $45 \%$ of the patients, and neutropenia was the cause for $61 \%$ of these modifications (13). An analysis of more than 20,000 patients with early-stage breast cancer treated with adjuvant chemotherapy found that $35 \%$ of the patients had dose reductions of more than $15 \%$, and $25 \%$ had treatment delayed more than 7 days. Overall, $56 \%$ of the patients were treated with a relative dose intensity of less than $85 \%$, including $67 \%$ of those older than 65 years (14).

Non-Hodgkin's malignant lymphomas (NHL). Despite progress in the development of target therapies with the introduction of monoclonal antibodies, chemotherapy remains the mainstay for the treatment of aggressive NHL. About $40 \%$ of patients achieve a cure with standard treatments including chemotherapy, plus eventual radiotherapy and/or rituximab. The prognosis and sensitivity to chemotherapy depend upon well-known prognostic factors from the International Prognostic Index being related to clinical and tumor extension parameters. The effectiveness of chemotherapy has been shown to be predicted on the basis of biological features, 
Table I. Results for selected regimens in epithelial ovarian cancer.

\begin{tabular}{lclccccccl}
\hline Regimen & $\begin{array}{c}\text { No. of } \\
\text { patients }\end{array}$ & Age (years) & N3/4 & $\begin{array}{c}\text { G-CSF } \\
\text { (days) }\end{array}$ & FN & Anemia & Plt & Deaths & Reference \\
\hline Carboplatin+paclitaxel & 1,055 & $19-85$ & $82 \%$ & - & NA & $7 \%$ & $11 \%$ & & Vasey (108) \\
Carboplatin+docetaxel & 1,055 & $19-85$ & $94 \%$ & - & NA & $11 \%$ & $10 \%$ & & Vasey (108) \\
PEC dose-dense & 22 & $39-70$ & & 6 & 0 & NA & NA & 0 & Pronzato (109) \\
Paclitaxel 175 & 184 & Median, 60 & NA & NA & $22 \%$ & $7 \%$ & $5 \%$ & NA & Omura (110) \\
Paclitaxel 250 & 188 & Median, 62 & NA & NA & $19 \%$ & $15 \%$ & $15 \%$ & NA & Omura (110) \\
Topotecan & 235 & $25-85$ & $77 \%$ & - & NA & $28 \%$ & $34 \%$ & $3.8 \%$ & Gordon (111) \\
\hline
\end{tabular}

as defined by a gene expression profile such as CD20 hyperexpression. Furthermore, chemotherapy is widely applied to other types of NHL, i.e. the follicular lymphoma and other rare entities (mantle cell lymphoma, etc.).

As far as aggressive NHL is concerned, the most widely employed chemotherapy regimen is the combination of cyclophosphamide, doxorubicin, vincristine and prednisone (CHOP). This regimen is considered myelotoxic, inducing grade 3-4 neutropenia in up to $70 \%$ of cases (15-18). Since aggressive NHL is considered chemosensitive, improvements were thought to be achieved by means of chemotherapy intensification; nevertheless, a definitive demonstration of superiority over the CHOP regimen has not yet been reached. In a reference study, it was compared to the so-called secondthird generation regimens (MACOP-B, m-BACOD, and PROMACE-CytaBOM) with superimposable results in terms of response, time-to-treatment failure and overall survival, and in favor of CHOP in terms of toxicity; in particular, myelosuppression appears to be higher with these new regimens (19). One theoretical reason for favoring secondthird generation regimens is that they are more aggressive and generically more dose intense (i.e. in MACOP-B, the administration of chemotherapy is weekly instead of 3-weekly); on the other hand, dose intensity of cyclophosphamide and doxorubicin is decreased for the concomitant use of other drugs. Therefore, myelosuppression remains the main toxicological problem in treating patients with NHL. This aspect is more important in older patients since the consequences of neutropenia have greater clinical relevance.

A series of studies report that the reduction of dose intensity can compromise the outcome of chemotherapy. A retrospective analysis on the association between the projected dose intensity of 22 studies and the observed response rate showed that increased dose intensity can improve the remission rate (20). Kwak et al observed in a series of 115 patients that a doxorubicin dose intensity of more than $75 \%$ was the most important prognostic factor (21). A retrospective analysis showed a long survival in patients that received a $>70 \%$ relative dose intensity of cyclophosphamide and doxorubicin (22).

Epelbaum et al reported that the prognosis of patients treated with CHOP was significantly different depending on the relative dose intensity applied during the first cycle: the 5 -year survival was $80 \%$ in patients treated with more than $70 \%$ of relative dose intensity and $32 \%$ in patients receiving less than $70 \%$ (23). A retrospective analysis of 653 patients treated with $\mathrm{CHOP}$ or CNOP for intermediate grade NHL showed that $43 \%$ of patients received suboptimal chemotherapy and $48 \%$ experienced a delay-reduction, usually neutropeniarelated, in chemotherapy dose. These dose reductions can affect therapeutic outcomes (24).

Furthermore, the reason that older patients with aggressive NHL have a worse prognosis than younger patients is likely due to the different dose intensity of chemotherapy received. Lee et al demonstrated that patients older than 59 years had a lower 5-year survival than younger ones (30\% versus 57\%), but this difference was not found in the subgroup of patients treated with a doxorubicin dose intensity of $>10 \mathrm{mg} / \mathrm{m}^{2} /$ week (25).

In spite of this evidence, the application of an optimal dose intensity in clinical practice is not always pursued or reached. In a survey of more than 4,500 patients carried out in the USA, a relative dose intensity $<85 \%$ for CHOP-based regimens was observed in about $50 \%$ of patients. An age $>60$ years, poor PS, advanced disease stage and no prophylactic use of G-CSF were independent predictors of a reduced relative dose intensity; in the same survey, the planned dose intensity was significantly lower in older patients (26). There is strong evidence from these large reviews that more than half of patients with NHL are 60 years or older, and delivery of the standard dose intensity may be particularly troubling in these patients.

Ovarian cancer. Most cases of epithelial ovarian cancer are detected in an advanced stage, and the treatment consists of a combination of aggressive surgery and variously timed chemotherapy. In the rare early presentation, adjuvant chemotherapy is applied after radical surgery. Strong evidence suggests the inverse relationship between chemotherapy effectiveness and the burden of disease.

In the last decade, the regimens applied to ovarian cancer patients are platinum compound-based schemes that range from single agent carboplatin to combinations including cisplatin or carboplatin and cyclophosphamide plus eventual anthracycline, or combinations of cisplatin or carboplatin plus a taxane. After disease relapse, the aim of treatment is palliative as a cure is seldom achieved. However, the regimens employed in this setting (taxane-platinum combinations in 'platinum-sensitive cases,' or topotecan or other agents in 'platinum-resistant cases') are reported to be myelotoxic due to multiple variables such as chemotherapy pretreatment, extension of disease and poor PS. 
Table II. Myelotoxic chemotherapies in adult sarcomas: toxicities and outcomes.

\begin{tabular}{|c|c|c|c|c|c|c|c|c|}
\hline \multirow[b]{2}{*}{ Author } & \multirow[b]{2}{*}{ Study } & \multirow{2}{*}{$\begin{array}{c}\text { No. of } \\
\text { patients }\end{array}$} & \multirow{2}{*}{$\begin{array}{l}\text { Use of G-CSF } \\
\text { days (dose) }\end{array}$} & \multicolumn{4}{|c|}{ Grade 3-4 hematological toxicity } & \multirow{2}{*}{$\begin{array}{l}\text { Results } \\
\text { RR/OS }\end{array}$} \\
\hline & & & & Netr. \% & Feb. neutr. \% & Anemia $\%$ & Plt $\%$ & \\
\hline Le Cesne (72) & Random & 294 & $14\left(250 \mu \mathrm{g} / \mathrm{m}^{2} / \mathrm{d}\right)$ & 90 & 16.6 & $\mathrm{Nd}$ & 45 & $23 \%$ \\
\hline Palumbo (71) & Phase II & 39 & $7(200 \mu \mathrm{g})$ & 34 & 13.0 & - & - & $59 \%$ \\
\hline De Pas (70) & Phase II & 23 & $8(5 \mu \mathrm{g} / \mathrm{kg} / \mathrm{d})$ & $\begin{array}{l}22 \mathrm{G} 3 \\
65 \mathrm{G} 4\end{array}$ & 35.0 & 11 & 10 & $50 \%$ \\
\hline Reichardt (69) & Phase II & 46 & $10(5 \mu \mathrm{g} / \mathrm{kg} / \mathrm{d})$ & $\begin{array}{l}17 \mathrm{G} 3 \\
83 \mathrm{G} 4\end{array}$ & 54.0 & $\mathrm{Nd}$ & $\begin{array}{l}15 \mathrm{G} 3 \\
35 \mathrm{G} 4\end{array}$ & $52 \%$ \\
\hline Frustaci (74) & $\begin{array}{l}\text { Random } \\
\text { Adjuvant }\end{array}$ & 104 & $8(300 \mu \mathrm{g} / \mathrm{d})$ & $35 \mathrm{G} 4$ & $\begin{array}{c}11.0 \\
(3 \mathrm{rd} \text { cycle })\end{array}$ & $\begin{array}{c}17 \% \text { G3 } \\
3 \% \mathrm{G} 4 / \mathrm{cy}\end{array}$ & $4 \mathrm{G} 4$ & $\begin{array}{c}\text { OS }>13 \%(2 y) \\
>19 \%(4 y)\end{array}$ \\
\hline Maurel (100) & Phase II & 60 & $10(5 \mu \mathrm{g} / \mathrm{kg} / \mathrm{d})$ & 46 & 24.0 & 41 & 24 & $38 \%$ \\
\hline Worden (73) & $\begin{array}{l}\text { Phase II } \\
\text { Random }\end{array}$ & 79 & $10(5 \mu \mathrm{g} / \mathrm{kg} /$ dose $)$ & $\begin{array}{l}49 \mathrm{SD} \\
87 \mathrm{HD}\end{array}$ & ND & $\begin{array}{l}23 \mathrm{SD} \\
57 \mathrm{HD}\end{array}$ & $\begin{array}{l}10 \mathrm{SD} \\
62 \mathrm{HD}\end{array}$ & $\begin{array}{l}15 \% \mathrm{SD} \\
21 \% \mathrm{HD}\end{array}$ \\
\hline
\end{tabular}

A retrospective analysis showed a direct relationship between tumor response and relative dose intensity for different regimens $(27,28)$. At least five randomized trials have compared two different doses of cisplatin: no difference in survival was observed in three trials (29-31), while a small but statistically significant difference was observed and there were some concerns about eligibility criteria in the remaining two $(32,33)$.

Regarding the efficacy of carboplatin, a randomized trial compared six courses at area under the curve (AUC) 6 against six courses at AUC 12. In the latter arm, an increase of only $20 \%$ instead of the planned $33 \%$ of dose intensity was obtained, and no differences were seen in progressionfree and overall survival, while the high dose produced more toxicity (34). Similar results were observed in a Danish study comparing AUC 4 to AUC 8 (35).

Regarding paclitaxel, Eisenahuer et al compared a bifactorial design of $135 \mathrm{mg} / \mathrm{m}^{2}$ with $175 \mathrm{mg} / \mathrm{m}^{2}$ and 3- or 24-h infusions (36). The response rate was superior for the high dose and prolonged infusion group, but resulted in more neutropenia.

On the basis of these studies, dose intensification up to now has shown poor results. But most studies with platinum compounds were carried out without hematopoietic growth factors, and the toxicity of the higher dose arm was greater, and a reduction of dose intensity was frequently applied with respect to the planned one (Table I).

Adult sarcomas. Adult sarcomas are a heterogeneous group of rare tumors from connective tissues including soft tissue sarcomas (STS), bone sarcomas, and Ewing's family sarcomas. Clinical management involves a multidisciplinary approach including radical local surgery with or without radiotherapy, and systemic therapy. The mainstays of chemotherapy are anthracyclines and oxaphosphorines in which a dose-response relationship was shown for both agents in preclinical models and clinical experiences. However, responsiveness has a wide range: from absolute refractory in some STS to intermediategood (bone sarcomas) and high (Ewing's sarcoma) with a real possibility of cure in the last two groups.

Regimens that include $\geq 70 \mathrm{mg} / \mathrm{m}^{2}$ of doxorubicin have achieved better responses compared with those using the same drug at lower doses. The combination of ifosfamide and doxorubicin was of particular interest to optimize frontline therapy. Many studies revealed an improved response rate with this combination, but there was no statistically significant difference in survival (37). The major thrust of clinical research has therefore been focused around dose intensification of available agents with the ultimate goal of improving the response rate and quality of response to sufficiently and favorably impact disease-free and overall survival. The major problem with this approach was prolonged, life-threatening myelosuppression. The use of hematological growth factors minimized this side effect.

Table II summarizes the most significant published studies of intensive chemotherapies in different STS. In all phase II studies on the use of intensified chemotherapy in adult sarcomas, the patients received prophylactic G-CSF and this resulted in an overall acceptable hematological toxicity.

Small cell lung cancer. Small cell lung cancer (SCLC) is a clinically aggressive disease with a median survival of only 3 months without treatment, and a significant sensitivity to both chemotherapeutic and radiation therapies. However, maintaining durable response and long-term remission has proved challenging. It has been well defined that patient-related prognostic factors are the stage, ECOG performance status, sex, age, and presence of paraneoplastic syndromes. Assuming that the dose-response relationship plays an important role in this disease, each of these variables can affect the outcome of chemotherapy chiefly by determining the level of toxicities and thus influencing and reducing the planned dose. In fact, 
as demonstrated by experimental in vivo models, a reduction in dose when the tumor is in the linear phase of the doseresponse curve results in the loss of capacity to cure the tumor. Thus, although complete remissions continue to be observed with dose reductions to as low as $20 \%$, residual tumor cells cannot be entirely eliminated, which thereby allows for eventual relapse to occur. Numerous clinical studies have confirmed these laboratory observations.

The combination chemotherapeutic regimens established more than a decade ago remain the standard of care. Two meta-analyses with more than 10,000 patients have found that regimens containing cisplatin and etoposide yielded a survival advantage $(38,39)$.

Retrospective data seem to support a correlation between dose intensity and survival. However, among all studies published in the last 5 years, only the trial of Stewart et al showed a significant survival benefit for patients in the intensified arm (40). Also, the shortening of treatment intervals resulted in an improved 2-year survival rate and 3 months in median survival, although there was no significant difference in the response rate and duration of response between treatment groups.

In a randomized phase II study carried out to assess the therapeutic index of two different platinum/etoposide regimens [attenuated-dose (AD) and full-dose (FD) plus prophylactic G-CSF], Ardizzoni et al enrolled 95 patients older than 70 years with limited (57\%) or extended (43\%) SCLC (41). The primary endpoint was the 'therapeutic success (TS),' defined as a patient receiving at least 3 cycles of chemotherapy at the planned dose and schedule, and having an overall response rate without G3 non-hematological toxicity and complications associated with hematological toxicity. The TSs were $10(36 \%)$ in the AD arm and $42(63 \%)$ in the FD arm. All outcome parameters were in favor of the full dose treatment protected by G-CSF. It was concluded that the policy of delivering attenuated doses of an effective regimen appears to provide insufficient therapeutic results in elderly patients with SCLC. All of these results suggest a possible detrimental effect by dose reduction to clinical outcome.

To improve results, additional drugs (epirubicin and cyclophosphamide or ifosfamide) and/or radiation therapy have been combined with PE in phase II and III clinical trials. Compared with the PE regimen, the response rates and survival rates improved in patients with extensive SCLC in the experimental arm (PCDE); however, hematological toxicity was more severe, and toxicity-related deaths were more frequent in the experimental arm (42). These new combinations have shown poor survival improvements in extended-stage SCLC, with a median survival of 9 to 12 months. A promising new chemotherapy combination of irinotecan plus cisplatin was compared with EP in a phase III trial in 154 extendedstage SCLC patients. The study was ended early when a significant survival advantage for irinotecan-cisplatin over EP was observed (median OS, 12.8 vs. 9.4 months, $\mathrm{P}=0.002$; and 2 -year OS, $19.5 \%$ vs. $5.2 \%$ ). No severe hematological toxicity was registered in either arm (43). These data were not confirmed at the ASCO Meeting 2005; treatment with weekly IP regimen resulted in no significant differences in overall survival with less myelosuppression and more diarrhea compared with standard EP (44). It is worth noting that the active drugs given in combination to treat ED SCLC have shown severe hematological toxicities only in poor performance status or elderly patients, and a moderate reduction of dose intensity has been shown to be moderately detrimental in achieving clinical benefit.

On the basis of the concept 'more is better,' the equation of reduced therapy = less clinical results, should be translated into increased therapy $=$ increased clinical results. Unfortunately, this is not the case as it seems doubtful that more toxic regimens can achieve better results.

In a study by the Hellenic Cooperative Oncology Group, 66 patients were divided into two groups to receive a standard or an intensified weekly regimen that increased the doses of carboplatin, epirubicin and ifosfamide by $25 \%$, and the doses of etoposide by $33 \%$ given on days 1, 2 and 3 with prophylactic G-CSF support. In the intensified group, the overall response rate was $91.8 \%$ (vs. $79.3 \%$ ), with a $45.9 \%$ (vs. $27.6 \%$ ) complete response rate, a median time-toprogression of 7.05 months (vs. 5.71) and a median survival of 10.16 (vs. 8.3) months. The toxicity was more severe in this group with G3-4 neutropenia in $16 \%$ of patients (vs. $0 \%$ ) and febrile neutropenia with hospitalization of $6 \%$ of patients; myelosuppression was the main toxicity, but at acceptable levels. The differences in response rate, time-to-progression and overall survival between the standard and intensified group were not statistically significant (45).

More significant advances have been seen in limitedstage disease. In combination with conformational radiation therapy, platinum-based regimens have produced a median survival time of 20 months, with $20 \%$ of patients achieving a durable remission at 5 years (46). The effect of scheduling combined radio-chemotherapy was studied in randomized trials to define the best sequence; a meta-analysis of 6 studies, with 2-year survival as the endpoint, demonstrated a trend towards long survival in the group in which early radiotherapy was given concurrently with chemotherapy. Hematological toxicity was increased, and any decrease in dose intensity should be avoided by the introduction of hematological growth factors $(47,48)$.

Germ cell tumors. Germ cell tumors still represent a unique model of curable solid tumors even with the presence of advanced disease (49). These outstanding results were obtained for two main reasons: the peculiar sensitivity of the tumor cells to some antineoplastic agents (mainly cisplatin), and a rational algorithm of treatment i.e. the right drugs and right schedules at the right time.

The 'quantity' of treatment depends on the prognostic category according to the IGCCCG classification (50). In patients with a good prognostic score, three courses of cisplatin, etoposide and bleomycin (BEP) is considered the standard first-line option given on either a 3- or 5-day schedule, while four courses of the same schedule are mandatory for more aggressive cancers (intermediate and poor risk categories).

The role of dose intensity is well recognized in achieving the goal of curing sensitive cancers such as advanced germ cell tumors. However, the impact of major schedules on neutropenia is well known as the first- and second-line therapy in this disease. It has been reported that up to 30$50 \%$ of patients are not able to receive a full-dose treatment 
Table III. Prophylactic use of filgrastim in breast cancer adjuvant treatment.

\begin{tabular}{|c|c|c|c|c|c|c|}
\hline Author & Patients & CSF & $\begin{array}{l}\text { Planned dose } \\
\text { on time }<85 \%\end{array}$ & $\begin{array}{c}\text { Hospitalization } \\
\text { for febrile } \\
\text { neutropenia }\end{array}$ & $\begin{array}{c}\text { Febrile } \\
\text { neutropenia }\end{array}$ & $\begin{array}{c}\text { Other G3-4 } \\
\text { toxicities }\end{array}$ \\
\hline \multirow[t]{3}{*}{ Rivera (56) } & $360 \mathrm{HR}(\leq 500 \mathrm{ANC})$ & G-CSF from day 2 & $12.1 \%$ & $4.4 \%$ & $11.1 \%$ & NA \\
\hline & 264 LR (>500 ANC) & to $\mathrm{ANC} \geq 10,000 / \mathrm{ml}$ & $4.2 \%$ & $0.8 \%$ & $2.6 \%$ & \\
\hline & 358 matched controls & & $5.6 \%{ }^{\mathrm{a}}$ & $4.7 \%$ & $9.4 \%$ & \\
\hline \multirow[t]{3}{*}{ Martin (58) } & $115 \mathrm{TAC}+\mathrm{G}$ & G-CSF & NA & NA & $3.5 \% \mathrm{a}$ & $20.0 \%{ }^{\mathrm{a}}$ \\
\hline & 109 TAC & & & & $23.8 \%$ & $50.4 \%$ \\
\hline & 224 FAC & & & & $1.3 \%$ & $26.7 \%$ \\
\hline \multirow[t]{2}{*}{ Roché (59) } & 100 FEC x6 & G-CSF, if required & NA & NA & $1.6 \%$ & NA \\
\hline & 100 FEC $x 3 \rightarrow$ DCT $x 3$ & & & & $2.5 \%$ & \\
\hline
\end{tabular}

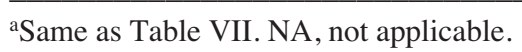

because of myelosuppression (51). Another schedule employed in the treatment of germ cell tumors was the combination of vinblastine, cisplatin, and ifosfamide (PVB) (52). This schedule was evaluated in the pre-growth factor era, and the rate of grade 4 neutropenia was close to $60 \%$. The chemotherapy schedule of VeIP (combination of vinblastine, ifosfamide, and cisplatin) was employed in the late 1980s with good results in seminoma and non-seminoma. Without the use of growth factors (unavailable at that time), the percentage of patients developing grade 4 leukopenia was as high as $50 \%$ with a possible $30-40 \%$ of patients developing grade 4 neutropenia.

A new dose-intense regimen is now being tested and consists of the combination of bleomycin, vincristine and cisplatin (BOP), alternating with bleomycin, etoposide and cisplatin (BEP), for a total of three BOP/BEP administrations (53). According to protocol, the administration of colonystimulating factors was not allowed, and it was left to the treating physician's discretion if neutropenia or neutropenic complications arose. Ninety percent of the patients developed either grade 3 or 4 neutropenia (grade 4 in $83 \%$ ). Thirteen patients were hospitalized a total of 18 times due to neutropenic complications. Moreover, 5/43 patients were treated with G-CSF for prolonged neutropenia. The results of this phase II dose intense regimen were impressive $(81 \%$ overall survival and $72 \%$ progression-free survival). For a population with an intermediate-poor prognosis, the addition of upfront G-CSF considerably reduced the risk of major neutropenia and neutropenic complications.

\section{The results on employment of G-CSF or pegfilgrastim to reduce myelotoxicity and maintaining dose intensity}

Breast cancer. Silber et al developed a risk model for neutropenic complications in patients with early-stage breast cancer treated with adjuvant chemotherapy (54). They found a significant relationship between the depth of absolute neutrophil count nadir in cycle 1 (ANC $\leq 500 / \mu 1 \mathrm{vs}>500 / \mu 1$ ) and subsequent neutropenic complications. The model has been validated in both retrospective and prospective studies
$(55,56)$, which predicted the likelihood of reducing the dose intensity of chemotherapy to less than $85 \%$ (55\% with ANC nadir $\leq 500 / \mu 1$ vs. $32 \%$ with ANC nadir $>500 / \mu 1$ ) and confirmed the role of hematological growth factors in increasing the rate of delivering dose intensity.

A meta-analysis of the results from 8 randomized controlled trials of G-CSF vs. placebo found that chemotherapy dose reductions or delay were doubled in patients receiving the placebo. The use of G-CSF decreases the likelihood of neutropenic complications in both the initial and subsequent cycles of therapy (57). The prophylactic use of G-CSF on febrile neutropenia after the docetaxel, doxorubicin and cyclophosphamide (TAC) regimen was assessed in an interim safety analysis of the GEICAM 9805 study. The TAC regimen (vs. conventional FAC regimen) has been shown to improve disease-free and overall survival in node-positive breast cancer, but at a higher rate of febrile neutropenia (Table III). The GEICAM 9805 studies compared 6 cycles of 3-weekly TAC vs. 6 cycles of 3-weekly conventional FAC in high-risk node-negative breast cancer $(58,59)$. A first group of patients (109 patients) treated with TAC did not or only occasionally received prophylactic G-CSF. Subsequently, the study was amended and a second group (115 patients) received G-CSF beginning with the first cycle of TAC. Within the limitations of a non-randomized comparison, the incidence of febrile neutropenia was substantially lower in the group receiving G-CSF (3.5\% vs. $23.8 \%$ ). Moreover, the rate of other G3-4 toxicities was consistently lower in the group receiving G-CSF (20.5\% vs. $50.4 \%)$.

Two randomized phase III trials that compared G-CSF, filgrastim and pegfilgrastim in patients with breast cancer treated with docetaxel and doxorubicin (Table IV) found that pegfilgrastim was comparable to filgrastim in reducing the incidence of febrile neutropenia and duration of grade 4 neutropenia $(60,61)$.

One study tested pegfilgrastim in a double-blind, placebocontrolled phase III study in breast cancer patients treated with docetaxel in both metastatic and non-metastatic disease. Pegfilgrastim markedly reduced febrile neutropenia, the frequency of hospitalizations and use of antibiotics (62). 
Table IV. Comparison of pegfilgrastim versus placebo or G-CSF in breast cancer patients.

\begin{tabular}{|c|c|c|c|c|}
\hline Author & Patients & Treatment & G-CSF & Comments \\
\hline Holmes (60) & $\begin{array}{l}\text { Pegfilgrastim, } 154 \\
\text { G-CSF, } 156\end{array}$ & $\begin{array}{l}\text { Docetaxel } 75 \mathrm{mg} / \mathrm{m}^{2}+ \\
\text { doxorubicin } 60 \mathrm{mg} / \mathrm{m}^{2}, \\
\text { x4 cycles }\end{array}$ & $\begin{array}{l}\text { Pegfilgrastim on day } 2 \\
\text { of each cycle, } \\
\text { G-CSF from day } 2 \\
\text { to ANC } \geq 10,000 / \mathrm{ml}\end{array}$ & $\begin{array}{l}\text { Pegfilgrastim was safe and effective } \\
\text { as daily Filgrastim in reducing } \\
\text { neutropenia and its complications. }\end{array}$ \\
\hline Green (61) & $\begin{array}{l}\text { Pegfilgrastim, } 77 \\
\text { G-CSF, } 75\end{array}$ & $\begin{array}{l}\text { Docetaxel } 75 \mathrm{mg} / \mathrm{m}^{2}+ \\
\text { doxorubicin } 60 \mathrm{mg} / \mathrm{m}^{2} \\
\text { x4 cycles }\end{array}$ & $\begin{array}{l}\text { Pegfilgrastim on day } 2 \\
\text { of each cycle, } \\
\text { G-CSF from day } 2 \\
\text { to ANC } \geq 10,000 / \mathrm{ml}\end{array}$ & $\begin{array}{l}\text { Pegfilgrastim was safe and effective } \\
\text { as daily Filgrastim in reducing } \\
\text { neutropenia and its complications. }\end{array}$ \\
\hline Vogel (62) & $\begin{array}{l}\text { Pegfilgrastim, } 463 \\
\text { placebo, } 465\end{array}$ & $\begin{array}{l}\text { Docetaxel } 100 \mathrm{mg} / \mathrm{m}^{2} \text {, } \\
\text { q } 3 \text { weeks }\end{array}$ & $\begin{array}{l}\text { Pegfilgrastim } 6 \mathrm{mg} \text { or } \\
\text { placebo on day } 2 \\
\text { of each cycle; if FN can } \\
\text { cross to pegfilgrastim } \\
\text { in placebo arm }\end{array}$ & $\begin{array}{l}\text { Naïve and pretreated patients; } \\
\text { chemotherapy moderately myelo- } \\
\text { suppressive; pegfilgrastim markedly } \\
\text { reduced febrile neutropenia. }\end{array}$ \\
\hline $\begin{array}{l}\text { Von Minckwitz } \\
\text { (112) }\end{array}$ & $\begin{array}{l}\text { Cohort A, } 390 \\
\text { cohort B, } 323 \\
\text { cohort C, } 236\end{array}$ & $\begin{array}{l}\text { Docetaxel } 75+ \\
\text { doxorubicin } 50+ \\
\text { cytoxan } 500 \mathrm{mg} / \mathrm{m}^{2} ; \\
\text { q } 21 \text { days x } 6-8 \text { cycles }\end{array}$ & $\begin{array}{l}\text { A) Filgrastim from } \\
\text { day } 3 \text { to } 12 \text {; } \\
\text { B) Pegfilgrastim on } \\
\text { day } 1 \text { or } 2 \text {; } \\
\text { C) Pegfilgrastim on } \\
\text { day } 1 \text { or } 2+ \\
\text { ciprofloxacin } 500 \mathrm{mg} \\
\text { b.i.d. on days } 5-14\end{array}$ & $\begin{array}{l}\text { Neutropenia and infections during } \\
\text { neoadjuvant TAC can be avoided } \\
\text { by primary prophylaxis with } \\
\text { pegfilgrastim+ciprofloxacin. }\end{array}$ \\
\hline
\end{tabular}

Non-Hodgkin's malignant lymphoma (NHL). Studies specifically carried out in patients with aggressive NHL examined the impact on myelotoxicity and dose intensity.

A randomized clinical trial in patients over 60 years has shown that the prophylactic use of G-CSF reduces the risk of complications due to neutropenia in patients receiving CHOP or CNOP (63). In this trial, a slight difference in delivered dose intensity was registered likely due to the favorable selection of patients, but a difference was not observed in complete remissions or overall survival. In a second study, the addition of G-CSF to CHOP resulted in a higher delivered dose intensity without affecting survival outcome; the cumulative days on antibiotics were fewer in the CHOP plus G-CSF arm, but the incidence of febrile neutropenia was not significantly lower (37.5\% vs. 44.0\%) (64). Notably, the relative dose intensity of cyclophosphamide and doxorubicin in the two arms was higher with and without G-CSF (about $90 \%$ ). In other words, it should be considered that patients likely to receive a lower dose intensity (at a level able to compromise clinical outcome) were not admitted to this study. Other randomized studies have shown that the prophylactic use of G-CSF is associated with dose intensity maintenance for different chemotherapy regimens. However, the use of prophylactic G-CSF did not reduce the occurrence of nonhematological toxicities, use of antibiotics or frequency of hospitalizations (65), and the higher dose intensity does not raise the CR rate or provide a more durable remission (66).

Pegfilgrastim has been employed in a randomized phase II study in which patients receiving etoposide, cisplatin, cytosine, arabinoside and prednisone were randomized to pegfilgrastim (one administration of $100 \mu \mathrm{g} / \mathrm{kg}$ ) or filgrastim (daily administrations of $5 \mu \mathrm{g} / \mathrm{kg}$ ) (67). Toxicity and tolerability were similar for both treatments. In a phase II study, Grigg et al randomized elderly patients to 60 or $100 \mu \mathrm{g} / \mathrm{kg}$ pegfilgrastim or $5 \mu \mathrm{g} / \mathrm{kg}$ filgrastim daily from day 2 , or no G-CSF after the first cycle of CHOP. After balancing risk factors between the $4 \mathrm{arms}, 100 \mu \mathrm{g} / \mathrm{kg}$ pegfilgrastim and filgrastim yielded similar results for the duration of grade 4 neutropenia, which were assumed in the primary endpoint of the study, and remained far longer in the no treatment arm. Interestingly, the cumulative number of G-CSF injections was 6 for pegfilgrastim and 60 for filgrastim. A full dose of cyclophosphamide and doxorubicin was delivered to $94 \%$ of patients in the filgrastim arm, $98 \%$ of patients in the $60 \mu \mathrm{g}$ pegfilgrastim arm and $100 \%$ of patients in the $100 \mu \mathrm{g}$ pegfilgrastim arm (68).

Adult sarcomas. Studies that used higher doses of anthracyclines or ifosfamide in combination chemotherapy with G-CSF support achieved a higher response rate in the range of $42-67 \%$. In a phase II study, Reichardt et al reported a response rate of $52 \%$ with a complete response rate of $22 \%$ in patients treated with a high-dose ifosfamide regimen and G-CSF support (10 days); all patients experienced grade 3-4 myelosuppression with a febrile neutropenia rate of $54 \%$ showing that, although toxic, this regimen is feasible and produces a high number of partial and complete remissions (69). 
Table V. Dose intensification chemotherapy studies on Ewing family tumors.

\begin{tabular}{|c|c|c|c|c|c|c|c|c|c|c|}
\hline Trial & $\begin{array}{l}\text { No. of } \\
\text { Pts }\end{array}$ & Age & Neutr G3/4\% & $\mathrm{N} \mathrm{d}$ & $\begin{array}{l}\text { Use of G-CSF } \\
\text { days (dose) }\end{array}$ & FN $\%$ & Anemia \% & Plt \% & Tox & $\mathrm{R}$ \\
\hline Marina (75) & 53 & 13.4 & $\begin{array}{l}\text { In: } 98 \\
\text { Main: } \\
100 \mathrm{SD} \\
83 \mathrm{HD}\end{array}$ & $\begin{array}{l}\text { In: } 17 \\
\text { Main } 49\end{array}$ & $\begin{array}{l}10-14 \\
(10 \mu \mathrm{g} / \mathrm{kg} / \text { dose })\end{array}$ & $\begin{array}{l}\text { In: } 89 \\
\text { Main: } \\
75 \text { SD } \\
89 \text { HD }\end{array}$ & $\mathrm{Nr}$ & $\begin{array}{l}\text { In: } 91 \\
\text { Main: } \\
100 \text { SD } \\
93 \text { HD }\end{array}$ & $\mathrm{Nr}$ & $\begin{array}{c}\text { CR } 82 \% \text {, } \\
\text { PR } 16 \%, \\
\text { 3-year 72\%, } \\
\text { EFS } 60 \%\end{array}$ \\
\hline $\begin{array}{l}\text { Felgenhauer } \\
\text { (76) }\end{array}$ & 24 & 10.5 & $\begin{array}{l}94 \\
\text { (of courses) }\end{array}$ & $\mathrm{Nr}$ & $\begin{array}{l}\mathrm{Nr} \\
(5-10 \mu \mathrm{g} / \mathrm{kg})\end{array}$ & 81 & $\begin{array}{l}84 \\
\text { (of courses) }\end{array}$ & 90 & $\mathrm{Nr}$ & $\begin{array}{c}\text { CR } 54 \% \text {, } \\
\text { TTP } 15.6 \text { m, } \\
\text { 2-year EFS } \\
50 \%\end{array}$ \\
\hline Womer (103) & 71 & 11 & $\begin{array}{l}\text { In: } 17 \\
\text { Main } 49\end{array}$ & $\mathrm{Nr}$ & $\begin{array}{l}\mathrm{Nr} \\
(5 \mu \mathrm{g} / \mathrm{kg} / \mathrm{d})\end{array}$ & $\begin{array}{l}\text { In: } \\
38 \text { (cy) } \\
\text { Main } \\
7 \text { (cy) }\end{array}$ & $\mathrm{Nr}$ & $\begin{array}{l}\text { In: } \\
19 \text { (cy) } \\
\text { Main } \\
45 \text { (cy) }\end{array}$ & $\begin{array}{c}1 \\
\text { (In) }\end{array}$ & NA \\
\hline
\end{tabular}

Pts, patients; plt, platelets; in, intensification treatment; main, maintenance treatment; SD, standard dose; HD, high dose.

In a phase II non-randomized trial with 23 patients, De Pas et al studied the feasibility of a chemotherapy regimen with high-dose ifosfamide plus adriamycin followed by G-CSF support in the treatment of advanced soft tissue adult sarcoma and observed a response rate of $50 \%$ (70). Twenty-three patients received 89 cycles of chemotherapy and 70 cycles were at full dose; the incidence of G3 and G4 neutropenia was $22 \%$ and $65 \%$, respectively, and febrile neutropenia occurred in $35 \%$ of patients, with four of them requiring hospitalization. However, the data were inconclusive on the efficacy of this treatment because of heterogeneity and a limited population.

In a phase II study on 39 patients treated with an intensive epirubicin/ifosfamide schedule, Palumbo et al showed a CR and PR rate of $13 \%$ and $46 \%$, respectively. Neutropenia was the most relevant hematological toxicity; $73 \%$ of chemotherapy courses were associated with neutropenia of all grades, but only $13 \%$ of patients had grade 4 and the incidence of febrile neutropenia was $13 \%$ (71).

Activity of a high-dose doxorubicin-containing regimen was compared with a conventional standard-dose regimen in adult patients with advanced soft tissue sarcomas (72). Objective responses were observed in $21 \%$ of patients in the intensified arm and $23 \%$ of patients in the standardchemotherapy arm (not significant), which did not confirm the expected dose-response relationship despite a $50 \%$ increase of doxorubicin dose intensity in the arm of high-dose chemotherapy. Hematological toxicity was the most frequent side effect, with grade 3-4 neutropenia documented in 92\% of patients in the standard arm and $90 \%$ in the intensified arm, and a higher incidence of febrile neutropenia in the intensified arm (16.6\% vs. $4.6 \%, \mathrm{P}=0.0004)$.

In a randomized phase II study, Worden et al compared the efficacy and toxicity of fixed dose doxorubicin in combination with high- or standard-dose ifosfamide in 79 patients with STS (73). Both arms were supported with prophylactic G-CSF. The authors concluded that this approach did not improve clinical results (1-year DFS), and toxicity was greater than expected in the intensified arm.

In the last 5 years, the role of intensified chemotherapy on STS in an adjuvant setting was examined in only one trial by Frustaci et al (74). In this study, 104 patients with grade 3-4 spindle cell sarcoma were randomized after surgery to receive adjuvant treatment with 5 cycles of $60 \mathrm{mg} / \mathrm{m}^{2}$ epirubicin on days 1 and 2 , and $1.8 \mathrm{mg} / \mathrm{m}^{2}$ ifosfamide on days $1-5$ with prophylactic G-CSF versus the control arm. The median survival time was higher among patients who underwent adjuvant therapy (75 months) compared with untreated patients (46 months); the risk reduction in treated patients was statistically significant $(\mathrm{P}=0.03)$ and the absolute improvement derived from chemotherapy was $13 \%$ at 2 years and $19 \%$ at 4 years. Although a cure is still difficult to achieve in adult STS, a significant delay in death is worthwhile, considering the short duration of treatment and absence of toxic deaths.

The Ewing's family of tumors consists of bone and soft tissue sarcomas that primarily affect children and young adults. The consistent use of multimodality therapy, including intensive chemotherapy, radiation therapy and surgery, has improved the survival of patients with localized sarcomas but, despite high complete remission rates, has not modified the prognosis among patients with metastatic disease at diagnosis.

In a study published in 1999, Marina et al treated 53 patients with both advanced and localized disease, with a sequence of surgery, induction CT (3 cycles of ifosfamide/ etoposide on days 1 to 3 and cyclophosphamide/doxorubicin on day 5 followed by G-CSF), local control with surgery and/or radiotherapy started at week 9 along with vincristine/ dactinomycin, and maintenance CT (4 alternating cycles of ifosfamide/etoposide and doxorubicin/cyclophosphamide at standard or high dose, followed by G-CSF) (75). Patients were randomized to two different cytoxan (CTX) maintenance schedules, standard dose (SD: CTX $1 \mathrm{~g} / \mathrm{m}^{2} / \mathrm{d}$ x2) or high dose (HD: CTX $1.5 \mathrm{~g} / \mathrm{m}^{2} / \mathrm{d} \mathrm{x} 2$ ). During induction therapy, $98 \%$ of 
Table VI. Impact of neutropenia in the treatment of germ cell tumors (no growth factors).

\begin{tabular}{lccc}
\hline Schedule & $\begin{array}{c}\text { GN } \\
\text { grade } 4(\%)\end{array}$ & $\begin{array}{c}\text { Febrile } \\
\text { neutropenia }(\%)\end{array}$ & Reference \\
\hline BEP & 13 & 13 & 51 \\
VIP-B & 49 & 46 & 51 \\
PVB & 59 & NR & 52 \\
VeIP & NR & 86 & 113 \\
PEI & $30-50$ & 26 & 80 \\
BOP/BEP & 83 & 28 & 53 \\
\hline
\end{tabular}

patients developed grade 4 neutropenia with $89 \%$ of patients requiring hospitalization for febrile neutropenia. During the maintenance phase, grade 4 neutropenia was present in $100 \%$ of patients in the standard arm and $93 \%$ of patients in the intensified arm $(75 \%$ and $80 \%$ of patients had febrile neutropenia, respectively). The patients achieved an excellent response to therapy with $82 \% \mathrm{CR}(86 \% \mathrm{SD}$ and $78 \% \mathrm{HD})$, $16 \% \mathrm{PR}$, and 3-year survival and EFS rates of $72 \% \pm 8 \%$ and $60 \% \pm 9 \%$, respectively. This study suggests that a doseintensifying treatment is feasible in all patients before the administration of local therapy, but only in a minority of patients after radiotherapy. Moreover, no significant benefit using an HD approach was achieved.

In a small study by Felgenhauer et al, 24 patients with metastatic disease received eight courses of VACIME chemotherapy $\left(2 \mathrm{mg} / \mathrm{m}^{2}\right.$ vincristine on day $0,20 \mathrm{mg} / \mathrm{m}^{2} / \mathrm{d}$ doxorubicin on days $0-3 ; 360 \mathrm{mg} / \mathrm{m}^{2} / \mathrm{d}$ cyclophosphamide on days $0-4 ; 1800 \mathrm{mg} / \mathrm{m}^{2} / \mathrm{d}$ ifosfamide on days $0-4$ and $100 \mathrm{mg} / \mathrm{m}^{2} / \mathrm{d}$ etoposide on days $0-4$ with G-CSF after each course). In the 7 th and 8 th course, doxorubicin was withdrawn (76). Surgical resection followed course 6 and radiotherapy followed the completion of all therapy. Grade 3-4 neutropenia was observed in $94 \%$ and febrile neutropenia in $81 \%$ of all cycles. Fifty-four percent of patients achieved CR after chemotherapy alone, the median time to recurrence was 15.6 months, and the 2- and 4-year EFS were 50\% and 45\%, respectively, suggesting that increased dose intensity improves the response rate in paediatric sarcomas, although the improvement in survival is less certain (Table V).

Small cell lung cancer. The impact on survival by shortening chemotherapy intervals has also been tested. In a trial by Steward et al in which 299 patients were randomized to 6 cycles of V-ICE every 3 or 4 weeks (standard and intensified arm, respectively); a second randomization was made to GM-CSF or a placebo (77). The incidence of grade 4 neutropenia was higher in the experimental arm (59\% vs. 49\%), but GM-CSF reduced the frequency of grade 4 neutropenia within each of these arms. Febrile neutropenia occurred in $54 \%$ of all patients, and there was no significant difference in the incidence between the two groups. The median duration of hospitalization was 12 days in the GM-CSF group and 13 days in the placebo group. There was no significant difference in the response rate or duration of response between treatment groups; there was a significant survival benefit for those in the intensified arm (443 vs. 351 days). The dose intensity treatment resulted in a $15 \%$ improvement in the 2-year survival rate $(\mathrm{P}=0.0014)$.

In another large randomized trial, 403 patients received 6 cycles of ACE chemotherapy every 3 weeks (control group) or every 2 weeks with G-CSF support (DI increased by $50 \%$ in the experimental group). Neutropenia G2-4 occurred in $21 \%$ of patients in the intensified arm with $33 \%$ treated with antibiotics, versus $83 \%$ in the control group with $34 \%$ of patients treated with antibiotics. Reported deaths from myelosuppression occurred in 6 patients in the intensified arm and 8 in the standard arm. In the experimental and control groups, $\mathrm{CR}$ was $40 \%$ and $28 \%(\mathrm{P}=0.02)$ with a total response rate of $78 \%$ and $79 \%$, respectively; survival rates were $47 \%$ and $39 \%$ at 12 months and $13 \%$ and $8 \%$ at 24 months (78).

Germ cell tumors. All regimens employed in the treatment of germ cell tumors are characterized by significant myelotoxicity (Table VI), which interferes with efficacy. The ASCO 2000 update recommendations suggest the use of hematopoietic colony stimulating factors in such curable disease after a

Table VII. Phase II randomized trials of dose-dense neoadjuvant chemotherapy.

\begin{tabular}{|c|c|c|c|c|c|c|}
\hline Author & Patients & Treatment & G-CSF (days) & $\mathrm{BCS} \%$ & $\mathrm{pCR} \%$ & $\mathrm{pN}-\%$ \\
\hline \multirow[t]{2}{*}{ Untch (83) } & 631 & E $150 \times 3$, T $250 \times 3$ for q 2 weeks & $3-10$ & $66.0^{\mathrm{a}}$ & $18.0^{\mathrm{a}}$ & $51.0^{\mathrm{a}}$ \\
\hline & & $\mathrm{E} 90+\mathrm{T} 175 \times 4$ for $\mathrm{q} 3$ weeks & & 10.0 & 10.0 & 42.0 \\
\hline \multirow[t]{2}{*}{ Green (84) } & 258 & T weekly x 12, FAC x 4 & None & NR & $28.8^{\mathrm{a}}$ & \\
\hline & & T 3 weeks x 4, FAC x 4 & & & 13.6 & \\
\hline \multirow[t]{2}{*}{ Jackisch (82) } & 395 & AD x 4 q 2 weeks & $5-10$ & 65.5 & 7.1 & 55.4 \\
\hline & 913 & AC x 4 q 3 weeks & & 74.9 & $14.1^{\mathrm{a}}$ & 60.7 \\
\hline \multirow[t]{2}{*}{ Euler (81) } & 151 & EC x 3 q 2 weeks & NR & 81.5 & 3.9 & \\
\hline & & EC x 3 q 3 weeks & & 80.0 & $9.5^{\mathrm{a}}$ & \\
\hline
\end{tabular}

A, doxorubicin; E, epirubicin; T, paclitaxel; D, docetaxel; C, cyclophosphamide; BCS, breast conservative surgery; pCR, pathological

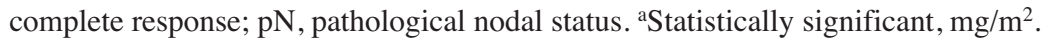


Table VIII. Dose-dense adjuvant chemotherapy for high-risk resectable breast cancer.

\begin{tabular}{|c|c|c|c|c|c|c|}
\hline Author & $\begin{array}{c}\text { No. of } \\
\text { patients }\end{array}$ & Study & Treatment & G-CSF & $\mathrm{mDI}$ & Comments \\
\hline $\begin{array}{l}\text { Venturini } \\
\text { GONO (88) }\end{array}$ & 1,214 & $\mathrm{Ph}$ III & $\begin{array}{l}\text { FEC x } 6 \text { q } 2 \text { weeks } \\
\text { FEC x } 6 \text { q } 3 \text { weeks }\end{array}$ & NR & $\begin{array}{l}93 \\
94\end{array}$ & $\begin{array}{l}\text { Non-significant reduction of HR } \\
\text { of death on DD arm }\end{array}$ \\
\hline Hudis (91) & 42 & $\mathrm{Ph}$ II & $\begin{array}{l}\text { A } \times 3, T \times 3, C \times 3 \\
q 2 \text { weeks }\end{array}$ & $3-10$ & 92 & Feasible and promising treatment \\
\hline Fornier (85) & 42 & $\mathrm{Ph}$ II R & $\begin{array}{l}\text { A x } 3, \mathrm{~T} \times 3, \mathrm{C} \times 3 \text { q } 2 \text { weeks } \\
\text { A x } 3,-\mathrm{TC} \text { q } 2 \text { weeks }\end{array}$ & $3-10$ & $\begin{array}{l}98 \\
87\end{array}$ & $\begin{array}{l}\text { Increased toxicity on DD arm: } \\
\text { hospitalization, febrile neutropenia, } \\
\text { incidence of RBC transfusions }\end{array}$ \\
\hline Citron (90) & 2,005 & $\mathrm{Ph}$ III $2 \times 2$ & $\begin{array}{l}\text { A x 4, T x 4, C x } 4 \text { q } 2 \text { weeks } \\
\text { A x 4, T x 4, C x } 4 \text { q } 3 \text { weeks } \\
\text { AC x 4, T x } 4 \text { q } 2 \text { weeks } \\
\text { AC x 4, T x } 4 \text { q } 3 \text { weeks }\end{array}$ & $\begin{array}{l}3-10 \\
3-10\end{array}$ & NR & $\begin{array}{l}\text { Dose-density significantly } \\
\text { improves DFS and OS; } \\
\text { DD decreases neutropenia }\end{array}$ \\
\hline Mobus (89) & $\begin{array}{l}1,169 \\
1,284\end{array}$ & $\mathrm{Ph}$ III & $\begin{array}{l}\mathrm{E} \times 3, \mathrm{~T} \times 3, \mathrm{C} \times 3 \text { q } 2 \text { weeks } \\
\mathrm{EC} \times 4, \mathrm{~T} \times 4 \text { q } 3 \text { weeks }\end{array}$ & $3-10$ & $\begin{array}{l}82 \\
90\end{array}$ & $\begin{array}{l}\text { Dose-density significantly } \\
\text { improves DFS and OS; } \\
\text { DD increases haematological } \\
\text { toxicity }\end{array}$ \\
\hline
\end{tabular}

A, doxorubicin; E, epirubicin; T, paclitaxel; C, cyclophosphamide; mDI, median dose intensity.

previous episode of febrile neutropenia, and discourage the reduction of cytotoxic drugs (79).

At the present time, G-CSFs are employed in the treatment of germ cell tumors to maintain dose intensity (i.e. the right therapy at the right time) and allow intensified schedules. As dose intensity is a pillar of successful chemotherapy in advanced germ cell tumors, centers such as Indiana University are now using G-CSF as the primary prophylaxis for intermediate and poor risk patients for each of the 4 cycles of BEP (80).

\section{5. 'Dose-dense' chemotherapy}

Breast cancer. The pharmacological hypothesis of dosedense chemotherapy was initially investigated in 4 randomized phase II studies whose results were controversial (Table VII): there was no evidence of better outcomes in two studies $(81,82)$, and significantly greater pathologic complete response plus a higher percentage of breast conservative surgery and pathological negative nodes in the other two $(83,84)$. However, a benefit of dose-dense chemotherapy was confirmed by Fornier et al (85). Two additional phase III trials tested the dose-dense neoadjuvant chemotherapy in locally advanced breast cancer with hematological growth factor support, but no measurable therapeutic benefits were demonstrated $(86,87)$. In an adjuvant setting, a dose-dense approach has been investigated in phase II and III clinical trials in patients considered at high risk of recurrence (Table VIII).

The effect of dose-dense chemotherapy was tested in three large prospective phase III studies: two presented in abstract form $(88,89)$, and the third was a CALGB (C9741) trial that compared sequential A-T-C with concurrent doxorubicin and cyclophosphamide followed by paclitaxel (AC-T) using dosedense (2-weekly) or conventional (3-weekly) schedules as adjuvant chemotherapy in 1973 patients with breast cancer (90). The dose-dense schedule was possible by using G-CSF. The dose-dense regimens resulted in significantly longer 3-year disease-free survival (85\% vs. $81 \%$ ) and 3-year overall survival ( $92 \%$ vs. $90 \%$ ), regardless of predictive factors. There was no difference in disease-free survival or overall survival between the sequential and concurrent arms. Grade 4 neutropenia was more common with conventional therapy, occurring in $33 \%$ of patients treated with conventional regimens and $6 \%$ of those receiving dose-dense regimens $(\mathrm{p}=0.0001)$. Moreover, the number of courses delayed because of hematological toxicity was lower in the dose-dense arm than in the conventional schedule arm (15\% vs. $38 \%)$. Furthermore, dose-dense chemotherapy significantly reduced the occurrence of contra lateral breast cancer ( $0.3 \%$ vs. $1.5 \%)$. CALGB 9741 showed not only the feasibility of this approach, but also the superiority of dosedense over conventional chemotherapy (91).

Non-Hodgkin's malignant lymphoma (NHL). The issue of dose-dense chemotherapy was also addressed in patients with aggressive NHL. The 'dose-dense approach' appeared feasible in different studies $(92,93)$, and preferable to increasing the dose per cycle, although maintaining the 14-day interval and G-CSF support means that increasing the dose of cyclophosphamide can be attempted (94).

The German High-Grade NHL Study Group demonstrated that patients aged over 60 receiving CHOP every 14 days fared better in time to treatment failure and overall survival compared to patients receiving CHOP at the standard 21-day interval (95). The same hypothesis was also evaluated in 
Table IX. Comparison between two different schedules of CHOP and CHOEP \pm G-CSF.

\begin{tabular}{lcccc}
\hline & CHOP 21 & CHOP 14 & CHOEP 21 & CHOEP 14 \\
\hline Adriamycin dose intensity, $\mathrm{mg} / \mathrm{m}^{2} /$ week & $97 \%$ x 16.6 & $93 \% \times 25$ & $96 \% \times 16.6$ & $83 \% \times 25$ \\
Complete remission rate & $60.1 \%$ & $76.1 \%$ & $70.0 \%$ & $71.6 \%$ \\
5-year event-free survival & $32.5 \%$ & $43.8 \%$ & $41.1 \%$ & $40.2 \%$ \\
5-year overall survival & $40.6 \%$ & $53.3 \%$ & $45.8 \%$ & $49.8 \%$ \\
Patients requiring RBC transfusion & $24.6 \%$ & $40.2 \%$ & $39.2 \%$ & $64.3 \%$ \\
Patients requiring platlet transfusion & $1.7 \%$ & $3.6 \%$ & $9.0 \%$ & $15.5 \%$ \\
Patients requiring antibiotics & $37.9 \%$ & $48.2 \%$ & $60.6 \%$ & $62.5 \%$ \\
\hline
\end{tabular}

CHOP and CHOEP 14 were given with G-CSF. RBC, red blood cells.

younger patients who were randomised and given $\mathrm{CHOP}$ or CHOP-etoposide every 14 or 21 days. A survival advantage for the shorter interval was observed, and the addition of etoposide resulted in a higher complete response rate and longer 5-year event-free survival. Interestingly, the chemotherapy acceleration with G-CSF did not increase nonhematological toxicity in these studies (Table IX). The duration of G-CSF treatment in the above-mentioned studies ranged from 6 to 10 days; in studies by the German HighGrade NHL Study Group, the duration was initially established in 10 days, and an attempt to reduce the treatment duration was made by the same group (96). Kloess et al compared the data of elderly patients that entered a new trial with CHOP plus G-CSF administered for only 7 days with the results of the previous trial with 10 days of G-CSF; the reduced dose allowed the accelerated administration of CHOP, but the rate of infections doubled from $2.4 \%$ to $5.2 \%$ (97). Moreover, two trials demonstrated the feasibility of the dose-dense approach employing pegfilgrastim instead of filgrastim. In these two studies, CHOP was administered every 14 days with pegfilgrastim (or filgrastim in one of them) with similar results in the application of the dose-dense chemotherapy $(98,99)$.

Adult sarcomas. In the only published study in which dosedense chemotherapy was employed, Maurel et al treated 57 chemotherapy-naïve patients with unresectable locally advanced or metastatic adult STS with doxorubicin for 3 days and a continuous infusion of ifosfamide over 5 days every 21 days, for 3 cycles with G-CSF for 7 days (100). Grade 3-4 neutropenia and febrile neutropenia were found in $46 \%$ and $24 \%$ of patients, respectively; there were no treatment toxicity-related deaths. After the completion of therapy, the overall response rate was $38 \%$ with a median time-to-progression of 24 weeks. Compared with the dose intensity schedules used in other trials, the current regimen had reduced toxicity in terms of G3-4 neutropenia and febrile neutropenia with a similar clinical efficacy.

Significant studies on the dose-dense treatment of Ewing's family sarcoma tumors have been published. The expected survival rate is between $70-80 \%$ in patients with locally advanced disease, while the clinical outcome for patients with metastatic disease is highly improved in comparison with past results, but still unsatisfactory. Many studies are exploring the use of high-dose chemotherapy with the rescue of peripheral blood progenitor cells $(101,102)$.
Womer et al conducted a prospective study in 73 children and adolescents with both localized and advanced Ewing's family sarcomas to determine whether G-CSF permits dose intensification (103). The alternated vincristine-doxorubicincyclophosphamide and ifosfamide-etoposide regimens, with G-CSF between courses were given in two phases ( 6 cycles of induction and 6 cycles of maintenance), and included primary tumor treatment with surgery and/or radiotherapy. Neutropenic fever occurred in $38 \%$ of induction cycles and $26 \%$ of maintenance cycles. This treatment was well tolerated and produced excellent results, showing the feasibility of the dose-dense approach.

Small cell lung cancer. Because of the high growth rate of SCLC, dose-intensive chemotherapy should theoretically have an impact on survival. However, after many years and several clinical trials, dose-intensive chemotherapy has failed to produce significant improvements in survival for these patients (104).

In a prospective multicenter phase III study examining the impact on overall survival of dose intensity and dose density, 244 patients with limited or extensive SCLC were randomised to receive standard $\mathrm{CDE}$ or intensified $\mathrm{CDE}$ with G-CSF (increase of dose by $25 \%$, DD by $33 \%$ and DI by $90 \%$ ). Myelosuppression was more severe in patients treated within the intensified arm with an overall incidence of grade 3 or 4 leukopenia similar in the two arms (over 90\%) and grade 4 leukopenia in $50 \%$ and $79 \%$ of patients in the standard and intensified arm, respectively. Febrile neutropenia occurred in $24 \%$ of patients treated with standard doses versus $34 \%$ of patients treated with intensified $\operatorname{CDE}(\mathrm{P}=0.102)$ with the $3 \%$ and $5 \%$ toxic deaths, respectively. In terms of response, there was no significant difference between the two arms; the overall response was $79 \%$ in the standard group and $84 \%$ in the intensified group, with $25 \%$ and $21 \%$ CR, respectively. After a median follow-up of 49 months for patients on the standard arm and 57 months for patients on the intensified arm, $90 \%$ and $87 \%$ have died (105).

In May 2005, Lorigan et al reported their phase III trial of standard ICE (4-week interval) versus dose-dense ICE (2-week interval) supported by 10 days of filgrastim and autologous blood recorded the day before the cycle and reinfused $24 \mathrm{~h}$ from the end of chemotherapy (106). The role of this autologous blood support does not appear to interfere with hematological recovery, in fact the granulocytopenia was 
significantly worse in the dose-dense arm. However, the authors suggest that the levels of natural killer cell precursors may be maintained in autologous salvaged blood, and this should justify why fewer patients in the dose-dense arm had febrile neutropenia. The conclusions of this trial are that dose-dense ICE with G-CSF and autologous blood transfusion shortens the treatment duration and reduces the occurrence of febrile neutropenia, but does not statistically improve overall survival, response rate or 2-year survival.

\section{Conclusions}

The results of this overview have confirmed that the role of chemotherapy and the maintenance of its doses and schedules are still of great importance, particularly in the so-called chemosensitive tumors. Hematological toxicity remains the main cause of dose reduction or course delay, and the reduction of dose intensity consequently and negatively affects clinical outcome. Hematopoietic growth factors such as granulocyte colony-stimulating factor (G-CSF), filgrastim and pegfilgrastim, are a family of cytokines that regulate the proliferation, differentiation, and viability of hematopoietic progenitor cells and mature blood elements. Overall, the ability of G-CSF to enhance hematopoiesis is widely used as part of treating certain cancers and has led to improved safety of high-dose chemotherapy.

Breast cancer treatments have been carefully reviewed, looking at the relationship between dose intensity and clinical response to chemotherapy. There is a wide debate about the concept that a reduction of dose intensity below $85 \%$ of the planned dose is detrimental in adjuvant and metastatic settings. The occurrence of myelotoxicity is strictly related to the characteristics of the employed regimens, including the interval between cycles. However, in standard schemes, neutropenia and febrile neutropenia are not generally so severe and prolonged to compromise the safety of the patient, but enough to induce dose reduction in a large percentage of patients, particularly older patients, thus influencing the final clinical results. The preventive use of G-CSF according to well-defined international guidelines overcomes the problem, and permits the maintenance of planned dose intensity. As far as dose-dense regimens are concerned, the findings are consistent with previous mathematical model predictions that shortening the interval between chemotherapy courses results in a more effective eradication of malignant cells and potentially improves survival. Also in this setting, the role of G-CSF is crucial to the success of therapy.

Non-Hodgkin's malignant lymphomas (NHL) are considered very sensitive tumors, and chemotherapy has the purpose of curing patients with aggressive disease. The most important toxicity of the employed regimens is myelosuppression, particularly in patients aged over 60 years, in advanced-stage disease and when the regimen is used as a salvage therapy. All of the studies that investigated the relationship between dose intensity and chemotherapy outcome suggest that dose reduction is detrimental to the response rate, time-to-treatment failure (TTF) and overall survival (OS). While increased dose intensity of CHOP or CHOP-like regimens by shortening the intervals between cycles improves OS, a planned or unplanned reduction in dose intensity of these regimens given at standard intervals decreases clinical outcome. The prophylactic use of G-CSF is associated with the maintenance of planned dose intensity, which is not warranted after a neutropenic event. Finally, dose-dense chemotherapy supported by G-CSF always improves clinical outcome in terms of OS.

Ovarian cancer is a clinical example of high sensitivity to platinum compounds and taxanes. When these drugs are employed together with surgery, a cure with a low incidence of hematological toxicity is truly achievable. However, considering the median age of patients (sixth decade of life on average) and therapeutic setting of these drugs used as a palliative second-line treatment, the incidence and severity of neutropenia and febrile neutropenia increases. Under these clinical conditions, the employment of G-CSF according to international guidelines is strongly recommended.

In retrospective analyses, it has been shown that a reduction in dose intensity decreases the response rate, and an increased dose of the platinum compound does not improve OS. The use of G-CSF has not yet been investigated in prospective and randomized trials, and no available data exist on the increase of dose-dense chemotherapy in ovarian cancer.

The heterogeneous group of adult soft tissue sarcomas (STS) includes poor chemosensitive malignancies and highly responsive diseases, such as the Ewing family tumors. The most employed drugs are anthracyclines and oxaphosphorines with a dose intensity considered to be of great importance to clinical outcome, even though these drugs have demonstrated a significant bone marrow toxicity, particularly when employed in intensified regimens. Conclusive data have not yet been found on the usefulness of increasing or decreasing doses in STS, but increasing dose intensity has shown higher response rates in a metastatic setting and prolonged disease-free periods with adjuvant treatments of Ewing family tumors. Of note, the correct prophylactic employment of G-CSF is necessary to avoid severe hematological toxicities in standard treatments and allow dose-dense chemotherapy, chiefly in Ewing sarcomas with higher expected survival rates in patients with locally advanced disease. It seems that for this group of diseases, the more rational strategy of surgery, radiotherapy and chemotherapy can be of greater importance than the pursuit of high dose intensity chemotherapy.

In the past, small cell lung cancer was considered the paradigm of chemo- and radiosensitivity and defined as 'potentially curable'. However, published studies have shown an increase in response rate, and a small improvement in OS. Since the first employment of the platinum and etoposide combination, no new or more active drugs have been found. The only progress has been the combined chemo- and radiotherapy, which is able to prolong progression-free survival in limited disease, with a high rate of hematological and extra hematological toxicities that require the use of G-CSF. There is no evidence showing the role of dose intensity in the achievement of responses, however, a detrimental effect by dose reduction has been indirectly demonstrated, particularly in older patients and when the duration of responses is considered.

Germ cell tumors represent an exclusive model of curable solid tumors even in presence of advanced disease as the cells are very sensitive to antineoplastic agents, and the well- 
established and profitable integration between chemotherapy and surgery. The role of dose intensity is well defined in obtaining a cure, and it is documented that a reduction of dose is detrimental and compromises the destiny of patients. In this scenario, the use of filgrastim and pegfilgrastim is mandatory and particularly important. Despite promising results, the trial of increasing dose-dense approach has not achieved the expected results, and future strategies for this disease are mainly focused on the recovery of relapsed patients and the employment of new drugs with biological targets.

In all the reviewed studies, the systematic use of G-CSF to prevent hematological toxicities and avoid a dose chemotherapeutic change is highlighted. Hematological growth factors are prescribed to control severe neutropenia and reduce the risk of infective diseases in patients treated with myelotoxic chemotherapies. Filgrastim should be administered daily for up to 2 weeks until neutrophil count has reached $10,000 / \mathrm{mm}^{3}$. In clinical trials, it has been demonstrated that the mean duration of G-CSF prophylaxis is up to 10-11 days. However, in daily clinical practice, many patients receive shorter courses of prophylaxis; and when G-CSF is employed for neutropenia treatment, the period of time is not well defined, but is usually up to the time of recovery from neutropenia. All of these clinical therapeutic approaches are not correct and certainly not compliant with the rules stated by international guidelines. A recent study examined the relationship between duration of prophylaxis and risk of hospitalization in patients receiving myelotoxic chemotherapy for NHL, breast cancer and lung cancer (107). The mean duration of filgrastim administration ranged from 4.3 days for lung cancer to 6.5 days for NHL. Of note, the multivariate analysis demonstrated a reduction in risk of hospitalization with each additional day of G-CSF administration. From this study and all studies on G-CSF prophylaxis, this strategy should be used for regimens in which the maintenance of dose intensity or increase of dose-dense is the most important tool for outcome. Whether the dose and duration of G-CSF administration are adequate, and pegfilgrastim plays an important role in this particular setting, the goal of maintaining dose intensity, improving the cure rate and avoiding hematological toxicities is easily achieved.

\section{Acknowledgements}

We thank Dr Ettore Bichisao, Innopharma, for careful manuscript revision and technical support in writing this review.

\section{References}

1. Skipper HE, Schabel FM and Lloyd HH: Dose-response and tumor cell repopulation rate in chemotherapeutic trials. Adv Cancer Chemother 1: 205-253, 1979.

2. Hryniuk $\mathrm{W}$ and Bush $\mathrm{H}$ : The importance of dose intensity in chemotherapy of metastatic breast cancer. J Clin Oncol 2: 1281-1288, 1984.

3. Norton LA: A gompertzian model of human breast cancer growth. Cancer Res 48: 7067-7071, 1988.

4. Gardner SN: A mechanistic, predictive model of dose-response curves for cell cycle phase-specific and non-specific drugs. Cancer Res 60: 1417-1425, 2000.

5. Norton L: Evolving concepts in the systemic drug therapy of breast cancer: Semin Oncol 24: S10.3-10.10, 1997.
6. Skipper HE: Kinetics of mammary tumor cell growth and implications for therapy. Cancer 28: 1479-1499, 1971.

7. Petit T, Borel C, Ghnassia JP, Rodier JF, Escande A, Mors R and Haegelé P: Chemotherapy response of breast cancer depends on HER-2 status and anthracycline dose intensity in the neoadjuvant setting. Clin Cancer Res 7: 1577-1581, 2001.

8. Focan C, Andrien JM, Closon MT, et al: Dose-response relationship of epirubicin-based first-line chemotherapy for advanced breast cancer: a prospective randomized trial. J Clin Oncol 11: 1253-1263, 1993.

9. Bonadonna G, Valagussa P, Moliterni A, Zambetti M, and Brambilla C: Adjuvant cyclophosphamide, methotrexate, and fluorouracil in node-positive breast cancer - the results of 20 years of follow-up. N Engl J Med 332: 901-906, 1995.

10. Bonadonna G, Zambetti M, Daidone MG, Pilotti S and Valagussa P: 30 years follow-up of randomised studies of adjuvant $\mathrm{CMF}$ in operable breast cancer: cohort study. BMJ 330: 217-222, 2005.

11. Bonneterre J, Roché H, Kerbrat P, et al: Epirubicin increases long-term survival in adjuvant chemotherapy of patients with poor prognosis, node-positive, early breast cancer: 10-year follow-up results of the French Adjuvant Study Group 05 Randomized Trial. J Clin Oncol 23: 2686-2693, 2005.

12. Muss HB, Woolf S, Berry D, et al: Adjuvant chemotherapy in older and younger women with lymph node-positive breast cancer. JAMA 293: 1073-1081, 2005.

13. Link BK, Budd GT, Scott S, et al: Delivering adjuvant chemotherapy to women with early-stage breast carcinoma: current patterns of care. Cancer 92: 1354-1367, 2001.

14. Lyman GH, Kuderer N, Agboola O and Balducci L: Evidencebased use of colony-stimulating factors in elderly cancer patients. Cancer Control 10: 487-499, 2003.

15. Sonneveld P, de Ridder M, van der Lelie, et al: Comparison of doxorubicin and mitoxantrone in the treatment of elderly patients with advanced diffuse non-Hodgkin's lymphoma using CHOP vs. CNOP. Ann Oncol 13: 2530-2539, 1995.

16. Luce JK, Gamble F, Wilson HE, et al: Combined cyclophosphamide, vincristine, prednisone therapy of malignant lymphoma. Cancer 28: 306-317, 1971.

17. Meyer RM, Browman GP, Samosh ML, et al: Randomised phase II of standard CHOP with weekly CHOP in elderly patients with non-Hodgkin's lymphoma. J Clin Oncol 13: 2386-2393, 1995.

18. Tirelli U, Errante D, Van Glabbeke M, et al: CHOP is the standard regimen in patients with $>70$ years of age with intermediate-grade and high-grade non-Hodgkin's lymphoma: results of a randomised study of the European Organization for Research and Treatment of Cancer Lymphoma Cooperative Study. J Clin Oncol 16: 27-34, 1998.

19. Fisher RI, Gaynor ER, Dahlberg S, et al: Comparison of a standard regimen (CHOP) with three intensive chemotherapy regimens for advanced non-Hodgkin's lymphoma. N Engl J Med 328: 1002-1006, 1993.

20. Meyer RM, Hryniuk WM and Goodyear MDE: The role of dose intensity of determining outcome in intermediate grade non-Hodgkin's lymphoma. J Clin Oncol 9: 339-347, 1991.

21. Kwak LW, Halpern J, Olshen RA, et al: Prognostic significance of actual dose intensity in diffuse large cell lymphoma. J Clin Oncol 8: 963-977, 1990.

22. Lepage E, Gisselbrecht C, Haioun C, et al: Prognostic significance of received dose intensity in non-Hodgkin's lymphoma patients: application to LNH-87 study. Ann Oncol 4: 651-656, 1993.

23. Epelbaum R, Haim N, Ben-Shahar M, et al: Dose intensity analysis for CHOP chemotherapy in diffuse aggressive large cell lymphoma. Isr J Med Sci 24: 533-538, 1988.

24. Picozzi VJ, Pohlma BL, Morrison VA, et al: Patterns of chemotherapy administration in patients with intermediate-grade nonHodgkin's lymphoma. Oncology 15: 1296-1306, 2001.

25. Lee KW, Kim DY, Yun T, et al: Doxorubicin-based chemotherapy for diffuse large cell lymphoma in elderly patients. Comparison of treatment outcomes between young and elderly patients and the significance of doxorubicin dosage. Cancer 98: 2651-2656, 2003

26. Lyman GH, Dale DC, Friedberg J, Crawford J, Richard I and Fisher RI: Incidence and predictors of low chemotherapy doseintensity in aggressive non-Hodgkin's lymphoma: a nationwide study. J Clin Oncol 22: 4302-4311, 2004. 
27. Levine L and Hryniuk W: The application of dose intensity in chemotherapy of ovarian and endometrial cancer. Semin Oncol 15: 12-19, 1987.

28. Repetto L, Pace M, Mammoliti S, et al: The impact of revived dose intensity on the outcome of advanced ovarian cancer. Eur J Cancer 29: 181-183, 1993.

29. Conte PF, Bruzzone M, Carnino F, et al: High dose versus low dose cisplatin in combination with cyclophosphamide and epidoxorubicin in ovarian cancer. J Clin Oncol 14: 1351-1356, 1996.

30. Colombo N, Piattelli M, Parma G, et al: Cisplatin dose intensity in advanced ovarian cancer. A randomized study of conventional dose-intense cisplatin monochemotherapy. Proc ASCO 12: 255, 1993.

31. McGuire WP, Hoskins W, Brady M, et al: Assessment of dose intensive in suboptimally debulked ovarian cancer: a Gynecology Oncology Study Group study. J Clin Oncol 13: 1589-1599, 1995.

32. Kaye SB, Levis CR, Paul J, et al: Randomized study of two doses of cisplatin with cyclophosphamide in epithelial ovarian cancer. Lancet 340: 329-333, 1992.

33. Ngan $\mathrm{H}$, Choo $\mathrm{Y}$, Cheung $\mathrm{M}$, et al: A randomized study of high versus low dose cisplatinum combined with cyclophosphamide in the treatment of advanced ovarian cancer. Chemotherapy 35 : 221-227, 1989

34. Gore M, Minwaring P, A'Hern R, et al: Randomized trial of dose intensity with single agent carboplatin in patients with epithelial ovarian cancer. J Clin Oncol 16: 2426-2434, 1998.

35. Jakobsen A, Bertelsen K, Andersen JE, et al: Dose-effect study of carboplatin in ovarian cancer. J Clin Oncol 15: 193-198, 1997.

36. Eisenhauer EA, ten Bokkel Hryniuk WW, Swenerton KD, et al: European-canadian trial of paclitaxel in relapsed ovarian cancer: high-dose versus low-dose and long versus short infusion. J Clin Oncol 12: 2654-2666, 1994.

37. Antman KH: Chemotherapy of advanced sarcomas of bone and soft tissue. Sem Oncol 19: 13-20, 1992.

38. Mascaux C, Paesmans M, Berghmans T, et al: A systematic review of the role of etoposide and cisplatin in the chemotherapy of small cell lung cancer with methodology assessment and meta-analysis. Lung Cancer 30: 23-36, 2000.

39. Pujol JL, Carestia L and Daures JP: Is there a case for cisplatin in the treatment of small-cell lung cancer? A meta-analysis of randomised trials of a cisplatin-containing regimen versus a regimen without this alkylating agent. Br J Cancer 3: 8-15, 2000 .

40. Steward WP, von Pawel J, Gatzemeier U, et al: Effects of granulocyte-macrophage colony-stimulating factor and dose intensification of V-ICE chemotherapy in small-cell lung cancer: a prospective randomized study of 300 patients. J Clin Oncol 20: 3947-3955, 2002.

41. Ardizzoni A, Favaretto A, Boni L, et al: Platinum-etoposide chemotherapy in elderly patients with small-cell lung cancer: results of a randomized multicenter phase II study assessing attenuated-dose or full-dose with lenograstim prphylaxis - A forza operativa nazionale italiana carcinoma polmonare and gruppo studio tumori polmonari veneto (FONICAP-GSTPV) study. J Clin Oncol 23: 569-575, 2005.

42. Pujol JL, Daurès JP, Rivière A, et al: Etoposide plus cisplatin with or without the combination of 4 '-epidoxorubicin plus cyclophosphamide in treatment of extensive small-cell lung cancer: a French Federation of Cancer Institutes Multicenter Phase III Randomized Study. J Natl Cancer Inst 93: 300-308, 2001.

43. Noda K, Nishiwaki Y, Kawahara M, et al: Irinotecan plus cisplatin compared with etoposide plus cisplatin for extensive small-cell lung cancer. N Engl J Med 346: 85-91, 2002.

44. Hanna NH, Einhorn L, Sandler A, et al: Randomized, phase III trial comparing irinotecan/cisplatin (IP) with etoposide/cisplatin (EP) in patients (pts) with previously untreated, extensive-stage (ES) small cell lung cancer (SCLC). ASCO Meeting: abs. 7004, 2005.

45. Skarlos DVMD, Samantas EMD, Pectasides DMD, et al: Weekly alternating non-cross-resistant chemotherapy for small cell lung cancer with a good prognosis: a study of the Hellenic Cooperative Oncology Group. Am J Clin Oncol 22: 87-93, 1999.

46. Turrisi AT 3rd, Kim K, Blum R, et al: Twice-daily compared with once-daily thoracic radiotherapy in limited small-cell lung cancer treated concurrently with cisplatin and etoposide. N Engl J Med 340: 265-271, 1999.
47. Stuschke $M$ and Pottgen C: Localized small-cell lung cancer: which type of thoracic radiotherapy and which time schedule. Lung Cancer 45: S133-S137, 2004.

48. Gui-Yuan Chen, Guo-Liang Jians, Li-Juan Wang, et al: Cisplatin/etoposide chemotherapy combined with twice daily thoracic radiotherapy for limited small cell lung cancer: a clinical phase II trial. Int J Radiat Oncol Biol Phys 61: 70-75, 2005.

49. Einhorn LH: Treatment of testicular cancer: a new and improved model. J Clin Oncol 8: 1777-1781, 1990.

50. International Germ Cell Cancer Collaborative Group. International Germ Cell Consensus Classification: a prognostic factor-based staging system for metastatic germ cell cancers. J Clin Oncol 15: 594-603, 1997.

51. Fosså SD, Kaye SB, Mead GM, et al: Filgtrastim during combination chemotherapy of patients with poor-prognosis metastatic germ cell malignancy. J Clin Oncol 16: 716-724, 1998.

52. Williams SD, Birch R, Einhorn LH, et al: Treatment of disseminated germ cell tumors with cisplatin, bleomycin and either vinblastine or etoposide. N Engl J Med 316: 1435-1440, 1987.

53. Anthoney DA, McKean MJ, Roberts JT, et al: Bleomycin, vincristine, cisplatin/bleomycin, etoposide, cisplatin chemotherapy: an alternating, dose intense regimen producing promising results in untreated patients with intermediate or poor prognosis malignant germ-cell tumors. Br J Cancer 90: 601-606, 2004.

54. Silber JH, Fridman M, Di Paola RS, Erder MH, Pauly MV and Fox KR: First-cycle blood counts and subsequent neutropenia, dose reduction, or delay in early-stage breast cancer therapy. J Clin Oncol 16: 2392-2400, 1998.

55. Thomas ES, Rivera E, Erder M, et al: Using first cycle nadir absolute neutrophil count (FCNANC) as a risk factor for neutropenic events. Proc ASCO 20: abs. 144, 2001.

56. Rivera E, Haim Em, Fridman M, et al: First-cycle absolute neutrophil count can be used to improve chemotherapy-dose delivery and reduce the risk of febrile neutropenia in patients receiving adjuvant therapy: a validating study. Breast Cancer Res 5: 114-120, 2003.

57. Lyman GH, Kuderer NM and Djulbegovic B: Prophylactic granulocyte colony-stimulating factor in patients receiving dose-intensive cancer chemotherapy: a meta-analysis. Am J Med 112: 406-411, 2002.

58. Martin M, Pienkowsky T, Mackey J, et al: Adjuvant docetaxel for node-positive breast cancer. N Engl J Med 352: 2302-2313, 2005.

59. Roché H, Fumoleau P, Spielmann M, et al: Five years analysis of the PACS 01 trial: 6 cycles of FEC 100 vs. 3 cycles of FEC 100 followed by 3 cycles of docetaxel (D) for the adjuvant treatment of node positive breast cancer. Breast Cancer Res 8: abs. 27, 2004

60. Holmes FA, O'Shaughnessy JA, Vukelja S, et al: Blinded, randomized, multicenter study to evaluate single administration pegfilgrastim once per cycle versus daily filgrastim as an adjunct to chemotherapy in patients with high-risk stage II or stage III/IV breast cancer. J Clin Oncol 20: 727-731, 2002.

61. Green MD, Koelbl H, Baselga J, et al: A randomized doubleblind multicenter phase III study of fixed-dose single-administration pegfilgrastim versus daily filgrastim in patients receiving myelosuppressive chemotherapy. Ann Oncol 14: 29-35, 2003.

62. Vogel CL, Wojtukiewicz MZ, Carroll RR, et al: First and subsequent cycle use of pegfilgrastim prevents febrile neutropenia in patients with breast cancer: a multicenter, double-blind, placebo-controlled phase III study. J Clin Oncol 23: 1178-1184, 2005.

63. Osby E, Hagberg H, Kvaloy $\mathrm{S}$, et al: $\mathrm{CHOP}$ is superior to CNOP in elderly patients with aggressive lymphoma while outcome is unaffected by filgrastim treatment: results of a Nordic Lymphoma Group randomized trial. Blood 101: 3840-3848, 2003.

64. Doorduijn JK, van der Holt B, van Imhoff GW, et al: CHOP compared with CHOP plus granulocyte colony-stimulating factor in elderly patients with aggressive non-Hodgkin's lymphoma. J Clin Oncol 21: 3041-3050, 2003.

65. Pettengell R, Gurney H and Radford JA: Dose-limiting neutropenia in high grade non-Hodgkin's lymphoma: a randomized controlled trial of G-CSF. Blood 80: 1430-1436, 1992. 
66. Zinzani PL, Gherlinzoni F, Storti S, et al: Randomized trial of 8 -week versus 12 -week VNCOP-B plus G-CSF regimens as front-line treatment in elderly aggressive non-Hodgkin's lymphoma patients. Ann Oncol 13: 1364-1369, 2002.

67. Vose JM, Crump M, Lazarus H, et al: Randomized, multicenter, open-label study of pegfilgrastim compared with daily filgrastim after chemotherapy for lymphoma J Clin Oncol 21: 514-519, 2003.

68. Grigg A, Solal-Celigny P, Hoskin P, et al: Open-label randomised study of pegfilgrastim vs. daily filgrastim as an adjunct to chemotherapy in elderly patients with non-Hodgkin's lymphoma. Leuk Lymphoma 44: 1503-1508, 2003.

69. Reichardt P, Tilgner J, Hohenberger P, et al: Dose-intensive chemotherapy with ifosfamide, epiubicin, and filgrastim for adult patients with metastatic or locally advanced soft tissue sarcoma: a phase II study. J Clin Oncol 16: 1438-1443, 1998.

70. De Pas T, De Braud F, Orlando L, et al: High-dose ifosfamide plus adriamycin in the treatment of adult advanced soft tissue sarcomas: is it feasible? Ann Oncol 9: 917-919, 1998.

71. Palumbo R, Neumaier C, Cosso M, et al: Dose-intensive firstline chemotherapy with epirubicin and continuous infusion ifosfamide in adult patients with advanced soft tissue sarcomas: a phase II study. Eur J Cancer 35: 66-72, 1999.

72. Le Cesne A, Judson I, Crowther D, et al: Randomized phase III study comparing conventional-dose doxorubicin plus ifosfamide versus high-dose doxorubicin plus ifosfamide plus recombinant human granulocyte-macrophage colony-stimulating factor in advanced soft tissue sarcomas: a trial of the European Organization for Research and Treatment of Cancer/Soft Tissue and bone sarcome group. J Clin Oncol 18: 2676-2684, 2000.

73. Worden FP, Taylor JMG and Biermann JS: Randomized phase II evaluation of $6 \mathrm{~g} / \mathrm{mq}$ of ifosfamide plus doxorubicin and granulocyte colony-stimulating factor (G-CSF) compared with $12 \mathrm{~g} / \mathrm{mq}$ of ifosfamide plus doxorubicin and G-CSF in the treatment of poor-prognosis soft tissue sarcoma. J Clin Oncol 23: 105-112, 2005.

74. Frustaci S, Gherlinzoni F, De Paoli A, et al: Adjuvant chemotherapy for adult soft tissue sarcomas of the extremities and girdles: results of the Italian randomized cooperative trial. J Clin Oncol 19: 1238-1247, 2001.

75. Marina NM, Pappo AS, Parham DM, et al: Chemotherapy dose-intensification for pediatric patients with Ewing's family of tumors and desmoplatsic small round-cell tumors: a feasibility study at St. Jude Children's Research Hospital. J Clin Oncol 17: 180-190, 1999.

76. Felgenhauer J, Hawkins D, Pendergrass T, et al: Very intensive, short-term chemotherapy for children and adolescents with metastatic sarcomas. Med Pediat Oncol 34: 29-38, 2000.

77. Steward WP, von Pawel J, Gatzemeier U, et al: Effects of granulocyte-macrophage colony-stimulating factor and dose intensification of V-ICE chemotherapy in small-cell lung cancer: a prospective randomized study of 300 patients. J Clin Oncol 20: 3947-3955, 2002.

78. Thatcher N, Girling DJ, Hopwood P, et al: Improving survival without reducing quality of life in small-cell lung cancer patients by increasing the dose-intensity of chemotherapy with granulocyte colony-stimulating factor support: results of a british medical research council multicenter randomized trial. J Clin Oncol 18: 395-404, 2000.

79. Ozer H, Armitage JO, Bennett CL, et al: 2000 update recommendation for the use of hematopoietic colony-stimulating factors: evidence-based, clinical practice guidelines. J Clin Oncol 18: 3558-3585, 2000.

80. Hinton S, Catalano PJ, Einhorn LH, et al: Cisplatin, etoposide and either bleomycin or ifosfamide in the treament of disseminated germ cell tumors. Final analysis of an intergroup trial. Cancer 97: 1869-1875, 2003

81. Euler U, Buehner M, Tio J, et al: Primary systemic chemotherapy (PST) with dose and time intensified epirubicin (E) and cyclophosphamide $(\mathrm{C})$ in locally advanced breast cancer (BC) - an attempt to identify predictive markers. Proc ASCO 21: abs. 126,2002

82. Jackisch C, von Minckwitz G, Eidtmann H, et al: Dose-dense biweekly doxorubicin/docetaxel versus sequential neoadjuvant chemotherapy with doxorubicin/cyclophosphamide/docetaxel in operable breast cancer: second interim analysis. Clin Breast Cancer 3: 276-280, 2002.

83. Untch M, Konecny G, Ditsch N, et al: Dose-dense sequential epirubicin-paclitaxel as preoperative treatment of breast cancer: results of a randomized AGO study. Proc ASCO 21: abs. 133, 2002.
84. Green MC, Buzdar AU, Smith T, et al: Weekly paclitaxel followed by FAC as primary systemic chemotherapy of operable breast cancer improves pathologic complete remission rates when compared to every 3-weeks paclitaxel therapy followed by FAC-final results of a prospective phase III randomized trial. Proc ASCO 21: abs. 135, 2002.

85. Fornier MN, Seidman AD, Theodoulou M, et al: Doxorubicin followed by sequential paclitaxel and cyclophosphamide versus concurrent paclitaxel and cyclophosphamide: 5-year results of a phase II randomized trial of adjuvant dose-dense chemotherapy for women with node-positive breast cancer. Clin Cancer Res 7: 3934-3941, 2001

86. Baldini E, Gardin G, Giannessi PG, et al: Accelerated versus standard cyclophoasphamide, epirubicin and 5-fluorouracil or cyclophosphamide, methotrexate and 5-fluorouracil: a randomized phase III trial in locally advanced breast cancer. Ann Oncol 14: 227-232, 2003.

87. Therrasse P, Mauriac L, Welnicka-Jaskiewicz M, et al: Final results of a randomized phase III trial comparing cyclophosphamide, epirubicin and fluorouracil with a doseintensified epirubicin and cyclophosphamide + filgrastim as neoadjuvant treatment in locally advanced breast cancer : an EORTC-NCIC-SAKK multicenter study. J Clin Oncol 21: 843-850, 2003.

88. Venturini M, Aitini E, Del Mastro L, et al: Phase II adjuvant trial comparing standard versus accelerated FEC regimen in early breast cancer patients. Results from GONO-MIG1 study. Breast Cancer Res Treat Suppl 1: S 9, 2003.

89. Mobus VJ, Untch M, Du Bois A, et al: Dose-dense sequential chemotherapy with epirubicin, paclitaxel and cyclophosphamide (ETC) is superior to conventional-dosed chemotherapy in high-risk breast cancer patients $(\geq 4+\mathrm{LN})$. First results of an AGO trial. Proc ASCO: abs. 513, 2004.

90. Citron ML, Berry DA, Cirrincione C, et al: Randomized trial of dose-dense versus conventionally scheduled and sequential versus concurrent combination chemotherapy as postoperative adjuvant treatment of node-positive primary breast cancer: first report of intergroup trial C9741/Cancer and Leukemia Group B Trial 9741. J Clin Oncol 21: 1431-1439, 2003.

91. Hudis C, Seidman A, Baselga J, et al: Sequential dose-dense doxorubicin, paclitaxel, and cyclophosphamide for resectable high-risk breast cancer: feasibility and efficacy. J Clin Oncol 17: 93-100, 1999.

92. Itoh K, Ohtsu T, Fukuda F, et al: Randomised phase II study of biweekly CHOP and dose-escalated CHOP with prophylactic use of lenograstim in aggressive non-Hodgkin's lymphoma: Japan Clinical Oncology Group Study 9505. Ann Oncol 13: 1347-1355, 2002.

93. Pronzato P, Bertelli G, Vigani A, et al: A feasibility study of accelerated polychemotherapy with cisplatin, epidoxorubicin and cyclophosphamide (PEC) in advanced ovarian cancer. Br J Cancer 73: 1425-1427, 1996.

94. Balzarotti M, Spina M, Sarina B, et al: Intensified CHOP regimen in aggressive lymphomas: maximal dose intensity and dose density of doxorubicin and cyclophosphamide. Ann Oncol 13: 1341-1346, 2002.

95. Preundschuh M, Trumper L, Kloess M, et al: Two-weekly or 3weekly CHOP chemotherapy with or without etoposide for the treatment of young patients with good-prognosis (normal LDH) aggressive lymphomas: results of the NHL-B1 trial of the DSHNHL. Blood 104: 626-633, 2004.

96. Preundschuh M, Trumper L, Kloess M, et al: Two-weekly or 3-weekly CHOP chemotherapy with or without etoposide for the treatment of elderly patients with aggressive lymphomas: results of the NHL-B2 trial of DSHNHL. Blood 104: 634-641, 2004.

97. Kloess M, Zeynalova S, Truemper L, et al: Effects of G-CSF schedule on leukocyte recovery and infection rate in the CHOP-14 regimen for elderly patients with aggressive lymphoma. Proc ASH: abs. 2402, 2004.

98. Bentley M, Marlton P, Horvath N, et al: Single dose per cycle Pegfilgrastim successfully supports full dose intensity CHOP-14 in patients over 60 years with non-Hodgkin's lymphoma and successfully mobilizes peripheral blood cell progenitors. Proc ASH 102: 2348, 2003.

99. Lopez A, Fernandez de Sevilla A, Castaigne S, et al: Pegfilgrastim supports the delivery of CHOP-R chemotherapy administered every 14 days: a randomised phase II study. Proc AH 103: 3311, 2004 
100. Maurel J, Fra J, López-Pousa A, et al: Sequential dose-dense doxorubicin and ifosfamide for advanced soft tissue sarcomas. Cancer 100: 7, 2004.

101. Rodriguez-Galindo C: Pharmacological management of Ewing sarcoma family of tumors. Expert Opin Pharmacother 5: 1257-1270, 2004.

102. Paulussen M, Ahrens S, Dunst J, et al: Localized Ewing tumor of bone: final results of the Cooperative Ewing's Sarcoma Study CESS 86. J Clin Oncol 19: 1818-1829, 2001.

103. Womer RB, Daller RT, Gallagher Fenton J, et al: Granulocyte colony stimulating factor permits dose intensification by interval compression in the treatment of Ewing's sarcoma and soft tissue sarcomas in children. Eur J Cancer 36: 87-94, 2000.

104. Klasa RJ, Murray N and Coldman AJ: Dose-intensity metaanalysis of chemotherapy regimens in small-cell carcinoma of the lung. J Clin Oncol 9: 499-508, 1991.

105. Ardizzoni A, Tjan-Heijnen VCG, Postmus PE, et al: Standard versus intensified chemotherapy with granulocyte colonystimulating factor support in small-cell lung cancer: a prospective European Organization for Research and Treatment of Cancer-Lung Cancer Group phase III trial 08923. J Clin Oncol 20: 3947-3955, 2002.

106.Lorigan P, Woll PJ, O'Brien ME, Ashcroft LF, Sampson MR and Thatcher N: Randomized phase III trial of dose-dense chemotherapy supported by whole-blood hematopoietic progenitors in better-prognosis small-cell lung cancer. J Natl Cancer Inst 97: 666-674, 2005.

107. Weycker D, Hackett J, Edelsberg J, et al: Are shorter courses of filgrastim prophylaxis associated with increased risk of hospitalisation? Ann Pharmacother 40: 402-407, 2006.
108. Vasey P: Preliminary results of the SCOTROC trial: a phase III comparison of paclitaxel-carboplatin and docetaxel-carboplatin as first line chemotherapy for stage Ic-IV epithelial ovarian cancer. Proc ASCO 20: 202a, 2001.

109. Pronzato P, Bertelli G, Vigani A, et al: A feasibility study of accelerated chemotherapy with cisplatin, epidoxorubicin, and cyclophosphamide (PEC) in advanced ovarian cancer. Br J Cancer 73: 1425-1427, 1996.

110. Omura GA, Brady MF, Look KY, et al: Phase III trial of paclitaxel at two dose levels, the higher dose accompanied by filgrastim at two dose levels in platinum pretreated epithelial ovarian cancer: an intergroup study. J Clin Oncol 21: 2843-2848, 2003.

111. Gordon AN, Fleagle JT, Guthrie D, et al: Recurrent epithelial ovarian caricinoma: a randomised phase III study of pegylated liposomal doxorubicin versus topotecan. J Clin Oncol 19: 3312-3322, 2001

112. Von Minckwitz G, Blohmer JU, Löhr A, et al: Primary prophylaxis with 3 weekly pegfilgrastim and ciprofloxacin effectively prevent (febrile) neutropenia and infection during neoadjuvant chemotherapy with docetaxel/doxorubicin/cyclophosphamide (TAC) in breast cancer patients. Proc ASCO abs. 8008, 2005.

113. Miller KD, Loehrer PJ, Gonin R and Einhorn LH: Salvage chemotherapy with vinblastine, ifosfamide, and cisplatin in recurrent seminoma. J Clin Oncol 15: 1427-1431, 1997. 